\title{
الغاز الطبيعي في العراق بين الحرق وجولات التراخيص
}

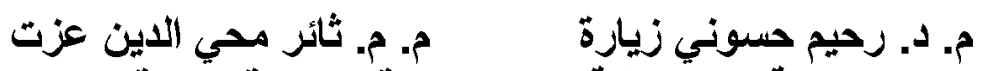 \\ جامعة بغداد- كلية الادارة والاقتصاد / قسم الاقتصاد
}

خلاصة البحث

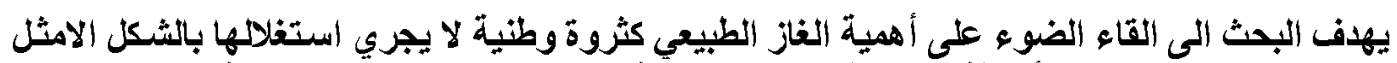

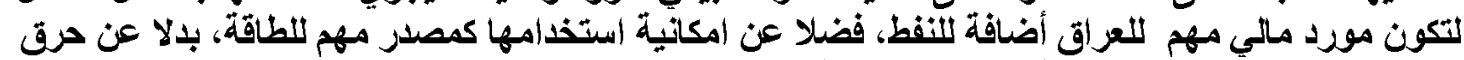

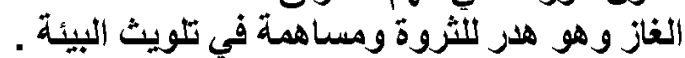

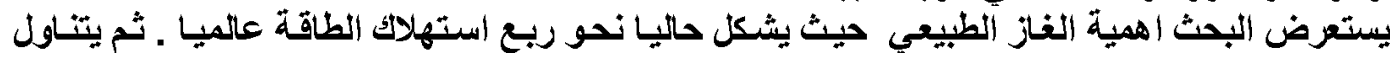

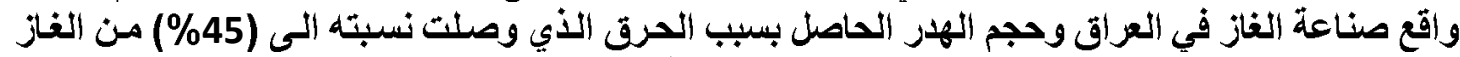

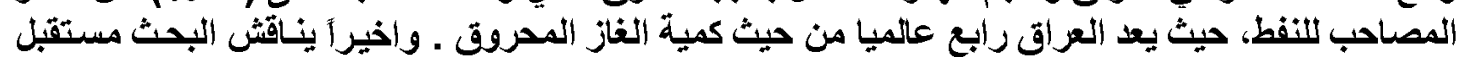

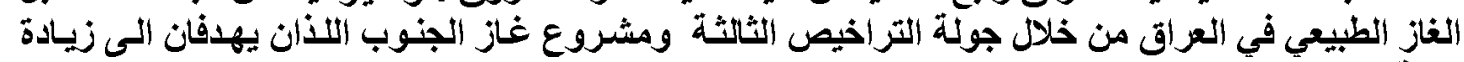

\section{SUMMARY}

The research aims to shed light on the importance of Natural gas as a National wealth is not being used optimally to be a financial resource is important to Iraq in addition to Oil, as well as could be used as an important Source of Energy, instead of burning gas is a waste of wealth and Contribute to the contamination of the environment. Research Reviews the importance of Natural gas, where is currently about a quarter of global energy consumption. Then deals with the reality of the gas industry in Iraq and winning because of the volume of waste incineration, which reached a rate $(45 \%)$ of the gas Associated with oil, where Iraq is fourth globally in Terms of the amount of gas Burned. Finally, this paper discusses the future of natural gas in Iraq through the Third Round of licenses and gas project which aimed to the south Increase the Proportion of gas exploitation in the future 
الاقدهمة

الغاز الطيعي ثروة وطنية هامه تلي في أهميتها الثروة النفطية، وبالتالي هو رافد من روافد تمويل

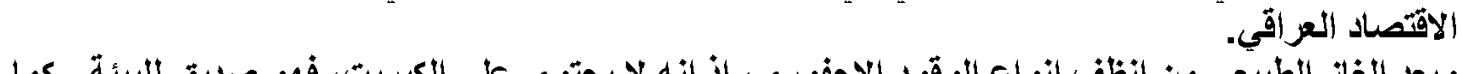

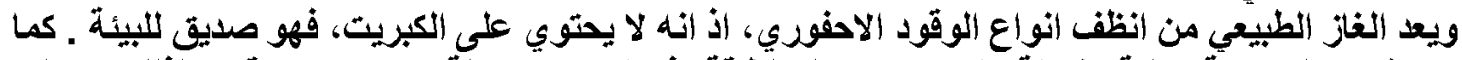

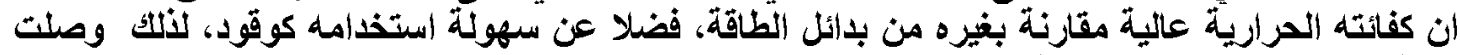

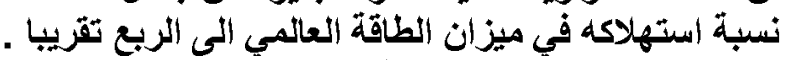

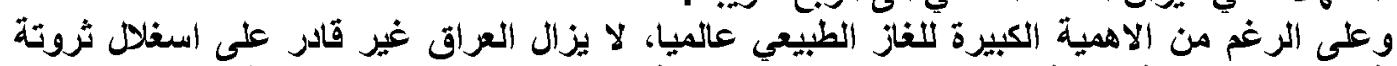

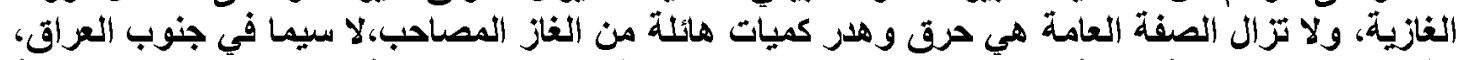

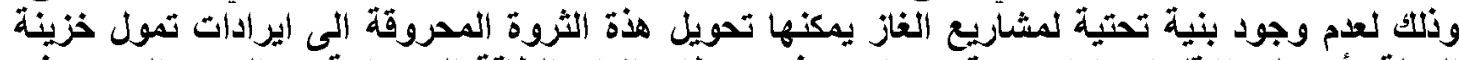

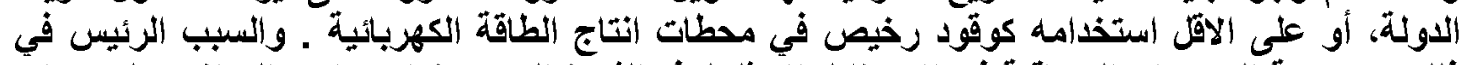

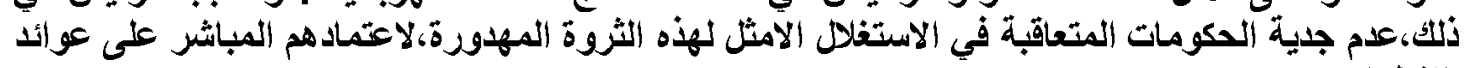

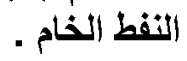

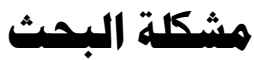

استمرار هلر الثاز الطبيعي بحرقه يوميا بكميات كبيرة منذ بدايات الصناعة النفطية العراقية ولحد الان

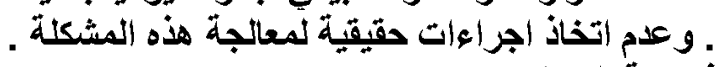

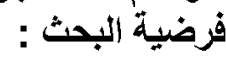

ان تبنّير كميات كبيرة من الغزاز المصـاحب لا يمكن تبريره اقتصادياً بوجود فرص حقيقية لأستغلاله بالثكل الامثل . أبائ.

\section{هدف البمث .}

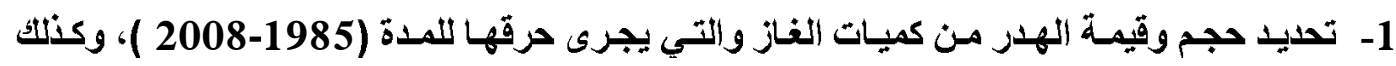

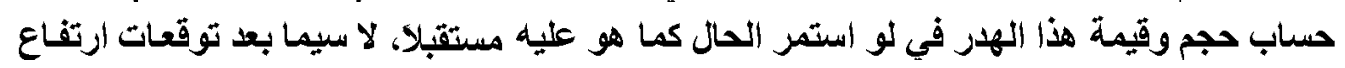

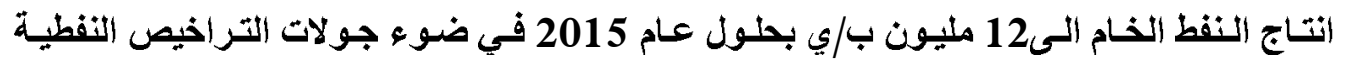
الاولى والثانية .

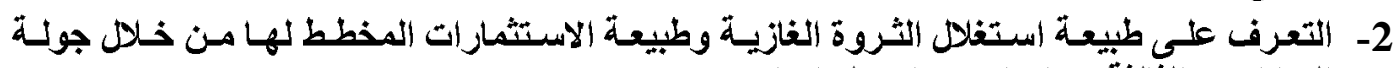

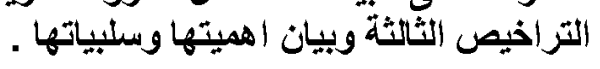

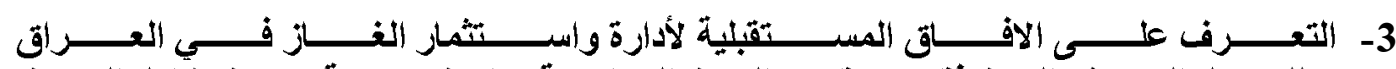

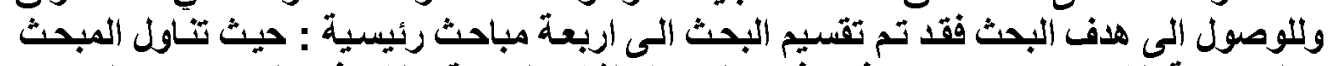

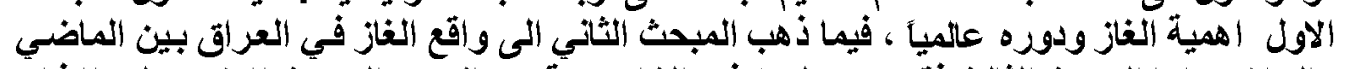

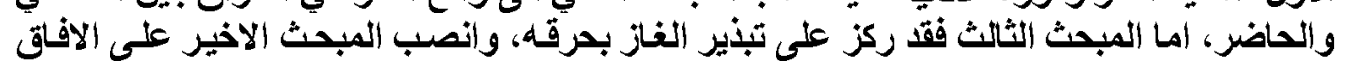

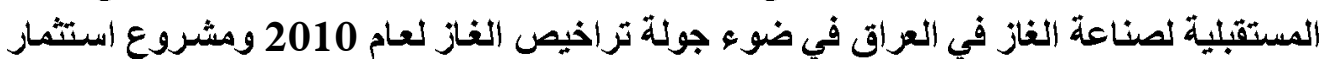
غاز الجنوب فضلا على مشروع خط الغاز العربي . 


\section{المبحث الاول \\ التطورات العالمية لتصنيع الغاز الطبيعي}

\section{المطلب الاول: تزايد دور الغاز الطبيعي في هيران الطاقة}

يتزايد دور الغاز الطبيعى تكريجياً في ميزان الطاقة العالمي نتيجة للخصائص التي يتميز بها، وسهولة

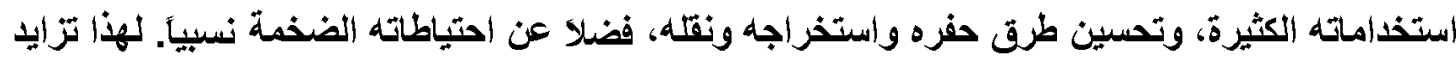
دوره في الاستهلاك العالمي الطاقة، فقد تطورت حصة الغاز الطبيعي من مجموع استهلاك الطاقة العالمي سنة

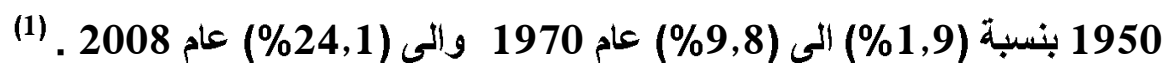

ان هذا التحول الحالي والمستمر الى الغاز الطبيعي مذهل بحسب المعايير التاريخية لان الغاز المستخلم

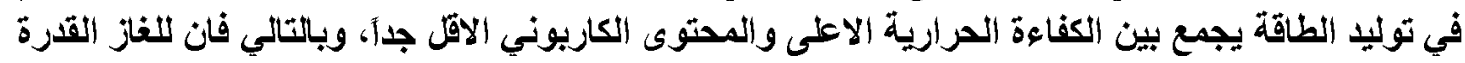

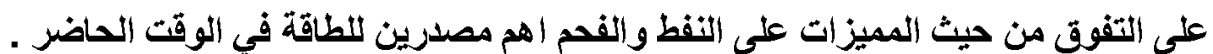

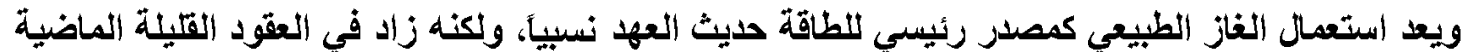

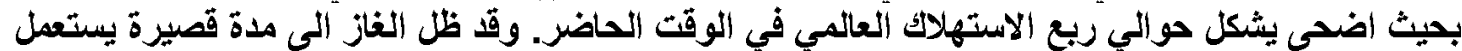

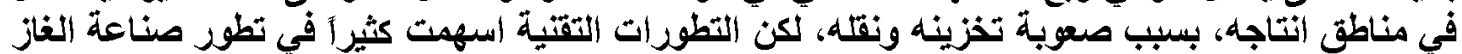

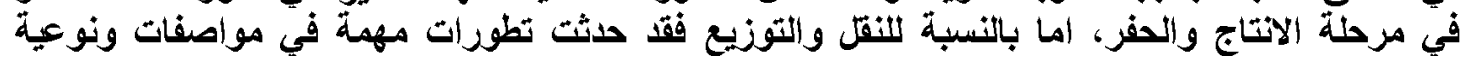

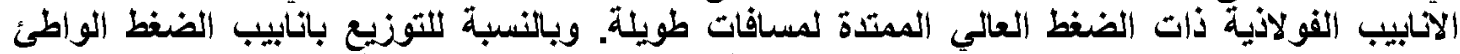

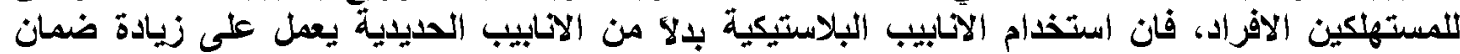

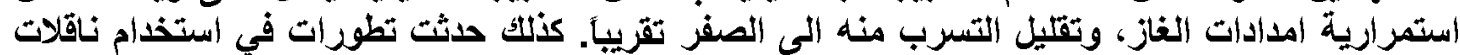

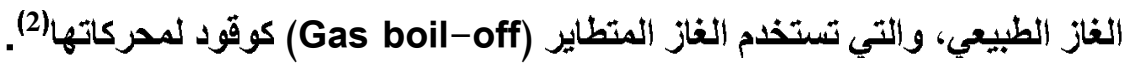

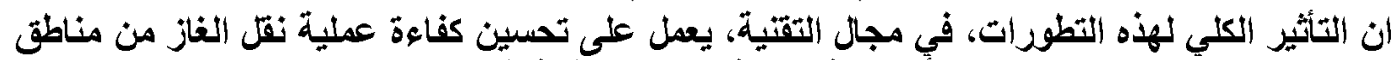

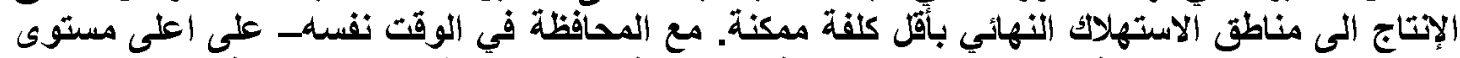

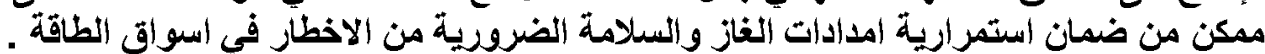

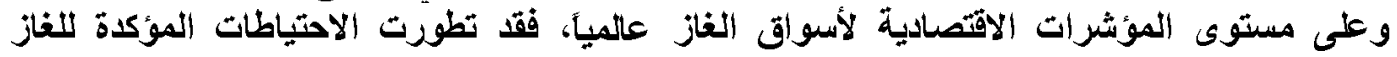

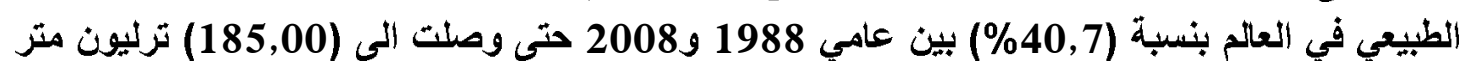
مكب في العام الاخير ـ فيما ازد/د معدل نمو الاتتاج العالمي من الغاز الطبيعي في عام 2008 بنسبة

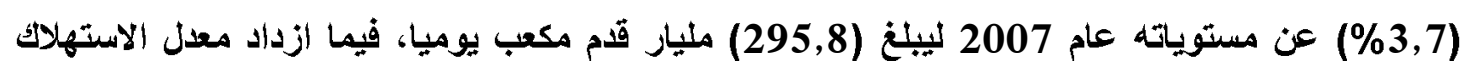
بنسبة (2.5\%) لنفس الفترة .

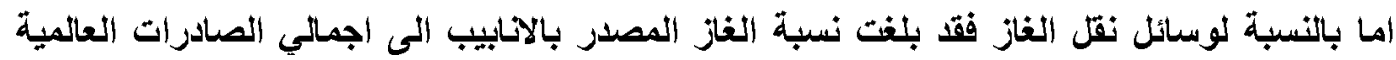

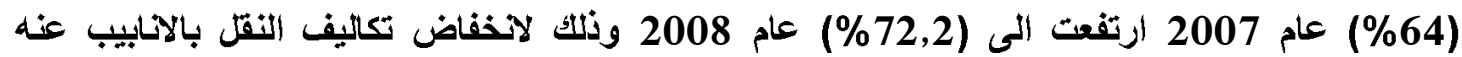
بالناقلات، فضلا عن ان النقل بالانابيب، يتجه في الغالب ، نحو الاول المجام المجاوة بعضها مع البعض الاخر . 
جدول (1)

\begin{tabular}{|c|c|c|c|c|c|}
\hline \multicolumn{2}{|c|}{$(2008-1988$} & \multicolumn{4}{|c|}{ مؤشرات الاحتياطي المثبت والانتاج والاستهلاك وأسعار الغاز الطبيعي عالمياً } \\
\hline 2008 & 2007 & 1998 & 1988 & 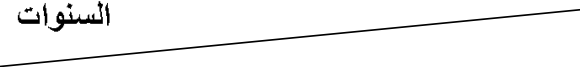 & المؤشرا \\
\hline 185,00 & 177,05 & 148,01 & 109,72 & المؤكد (تريليون متر مكب) & الاحتياط \\
\hline 295,8 & 285,00 & 219,9 & 179,8 & يار قدم مكب/ليومي) & 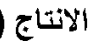 \\
\hline 291,3 & 284,3 & 215,5 & 176,8 & (مليار قام مكب/لومي) & الاستهلا \\
\hline & & & & غناز الطبيعي (مليار قام مكعب يومي) & صادرات \\
\hline 27,83 & 39,37 & & & غاز طبيعي مسيل & - \\
\hline 72,17 & 70,63 & & & بواسطة الانابيب & - \\
\hline 100 & 110 & & & اجمالي الصادرات & - \\
\hline 72,17 & 64,2 & & & نسبة الغاز المصدر بالآابيب الى اجمالي الصادرات & - \\
\hline & & & & رل الغاز (دولار امريكي اكل مليون (Btu ) & 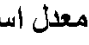 \\
\hline 12,55 & 7,73 & 3,05 & $\mathbf{3 , 3 4}$ & اليابان & - \\
\hline 12,61 & 8,93 & 2,26 & 2,36 & الاتحاد الأوربي & - \\
\hline 10,79 & 6,01 & 1,86 & - & المملكة المتحدة & - \\
\hline 8,85 & 6,95 & 2,08 & - & الولايات المتحدة الامريكية & - \\
\hline 11,95 & 6,17 & 1,42 & - & كندا & - \\
\hline 16,76 & 11,95 & 2,16 & 2,56 & منظمة (OECD) & - \\
\hline
\end{tabular}

1. B.P.Statistical Review of World Energy, June, 2009.

2. بالنسبة للصادرات مأخوذة عن تقرير الامين العام السنوي السادس والثلاثون. منظمة اوابك، 2009

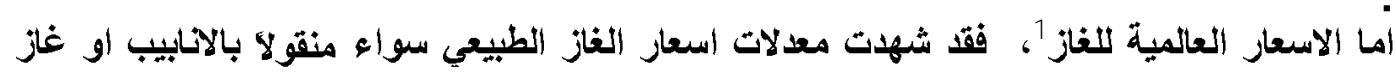

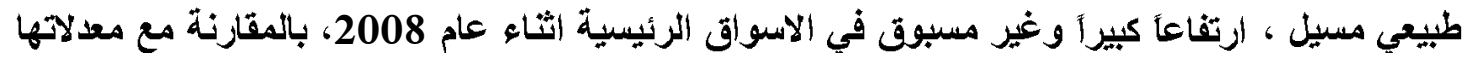

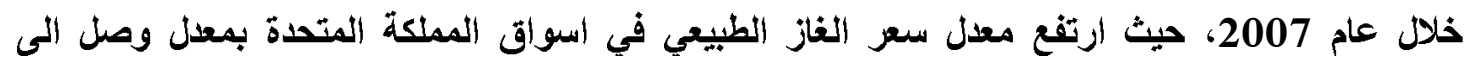
(\%79,5)، كما ارتفع معدل سعر الغاز الطبيعي الواصل الى اليابان بحدود (62,4\%)، وارتفع معدل سعره

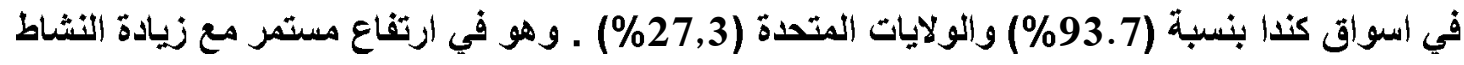

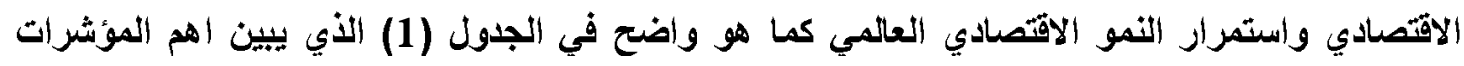
الاقتصادية العالمية لاسواق الغاز الطبيعي للمدة (1988 - 2008) ـ 
اما بالنسبة لمستقبل الغاز الطبيعي، فهو مستقبل واعد بكل المقاييس. حيث تشير توقعات دراسات الطاقة

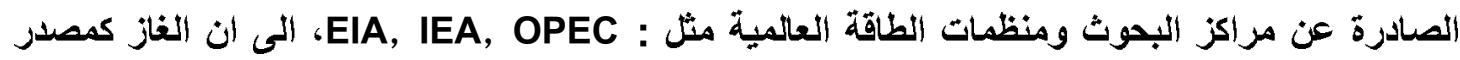

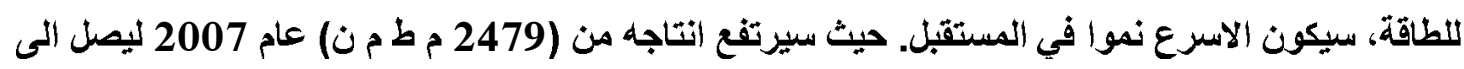

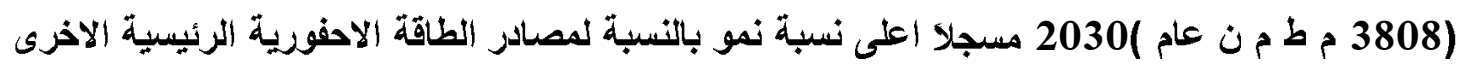

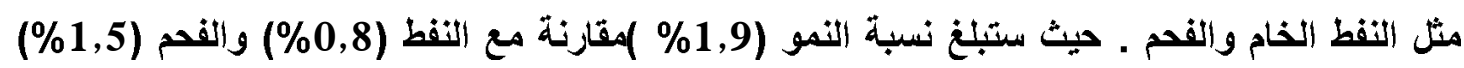

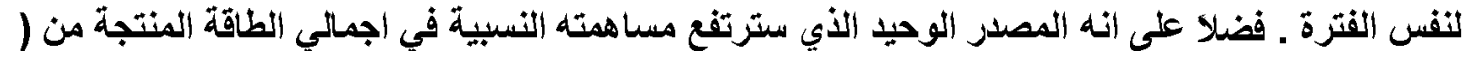

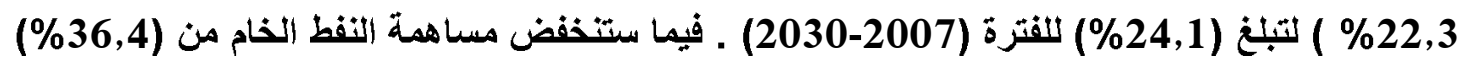
الى (31\%) في حين سيحافظ الفحم على نفس النسبة (28\%) لنفس الفترة كما هو موضح في جدول (24).

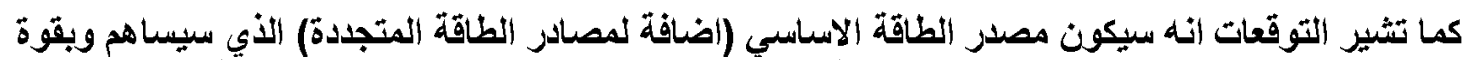

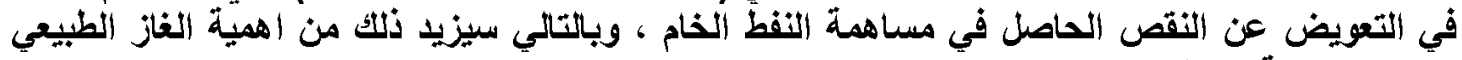
مستثبلا بلبرجة كبيزة .

جدول (2)

مؤشرات مصادر الطاقة الاساسية عالمياً والتوقعات حتى 2030

\begin{tabular}{|c|c|c|c|c|c|}
\hline \multicolumn{2}{|c|}{ المساهمة النسبية \% } & \multirow{2}{*}{$\begin{array}{c}\text { \% النمو } 2030-2007 \\
\text { 2007 }\end{array}$} & \multicolumn{2}{|c|}{ حجم الانتاج/ م ط م ن } & \\
\hline 2030 & 2007 & & 2030 & 2007 & \\
\hline 31 & 36,4 & 0,8 & 4902 & 4045 & النفط \\
\hline 28,1 & 28,2 & 1,5 & 4438 & 3129 & الفحم \\
\hline 24,1 & 22,3 & 1,9 & 3808 & 2479 & الغاز \\
\hline
\end{tabular}

OPEC, ENERGY OUTLOOK, 2009 : المصدر : الجدول من اعداد الباحث حسب بيانات

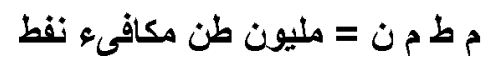

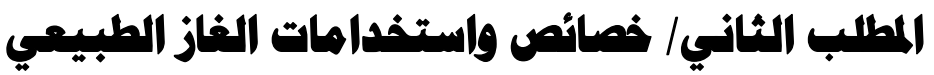

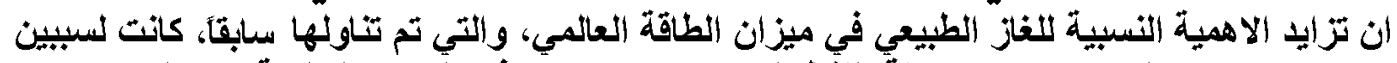

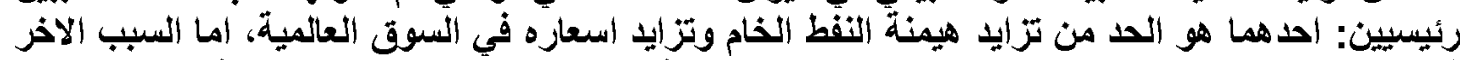

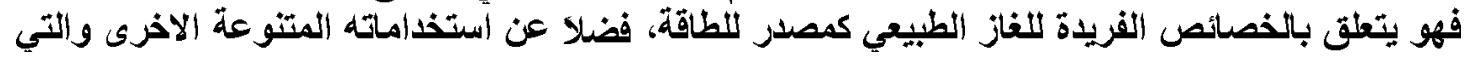

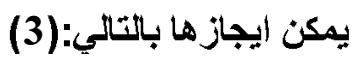

\section{خصائص الغاز الطبيسي}

1. أرتفاع القيمة الحرارية للغاز وبالتالي استخدامه بكفاءة عالية مقارنة مع الثغاز الصناعي.

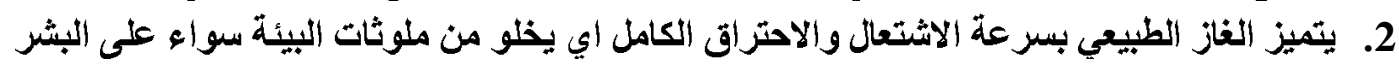

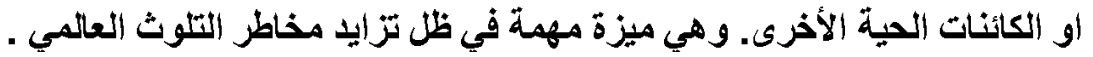

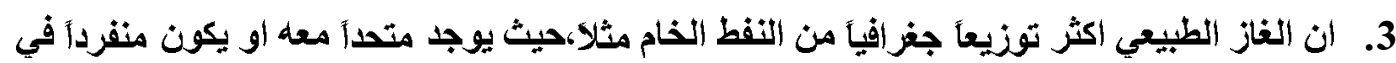

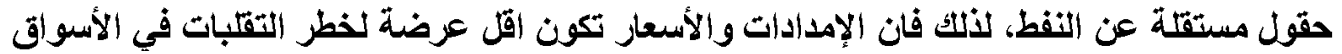
العالمية . 4. كلفة القرصة الببلية للغاز الطبيعي منخفضة جأ حيث كان يحرق منذ سنوات ولا يزال في بعض الفض دول العالم . 5. يتميز بسهولة استخر اجه ونقله وبتكاليفه المنخفضة بعد تطور تقنية صناعة الانابيب . 


\section{امسا اهم استخدامات الغاز الطبيعي فهي:}

1. توليد الطاقة الكهريائية والحرارية للاستخدامات المنزلية والتجارية والصنائية الصناعية . 2.

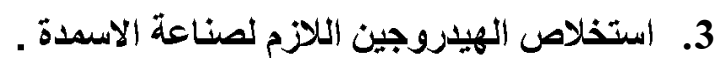

4. صناعات الطاقة المكثفة حيث يستخدم في اختزال الالمونيوم والحديد والفولاذ وانتاج الاسمدة والزجاج و اليوريا . 5. وقود لوسائل النثل البرية والجوية والبحرية . 6.

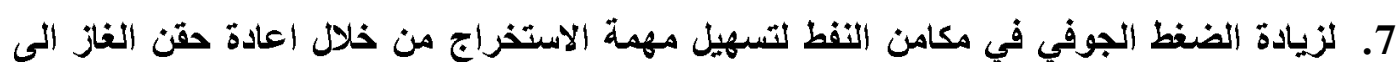

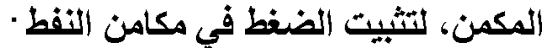
8. في التبريد الصناعي لاتتاج النتروجين والاوكسجين و السائلين . 


\section{المبـث الثاني/ واقع الغاز الطبيـي في العراق بين الماضي والحاضر}

\section{المطلب الاول : احتياطي الغاز العراقي}

يمتلك العراق احتياطيات نفطية ضخمة مؤكدة تبليغ (143,1) مليار برميل، وهي في طور الزيادة نتيجة

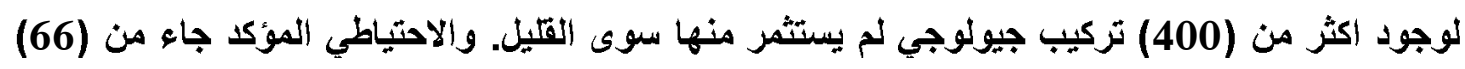
حقلا فقط، كما اكد ذلك الناطق الرسمي باسم وزارة النفط. فيما يبإغ الاحتياطي المحتمل (500) مليار برميل

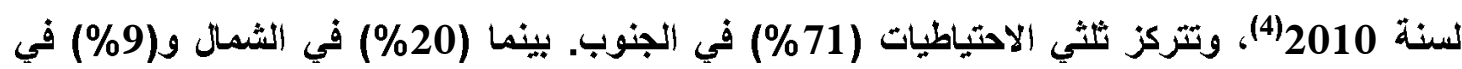

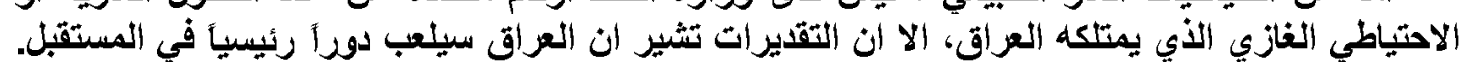

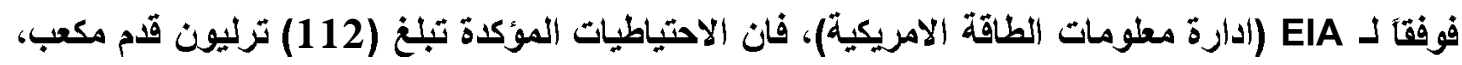
ويمثل المرتبة العاشرة في العالم. ويقتر ان (70\%) من هذه الاحتياطيات في البصرة. اما الاحتياطيات

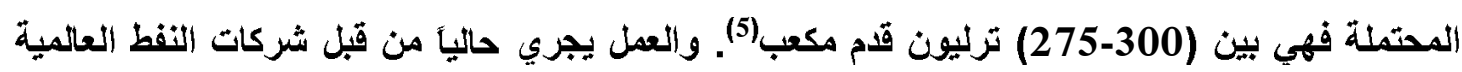

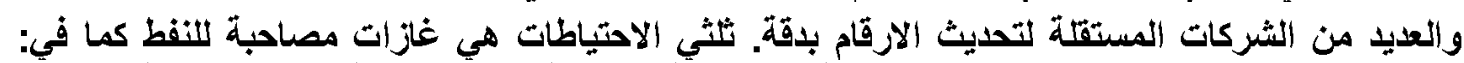

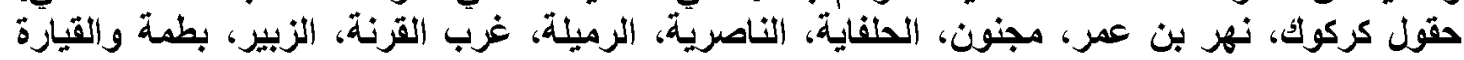

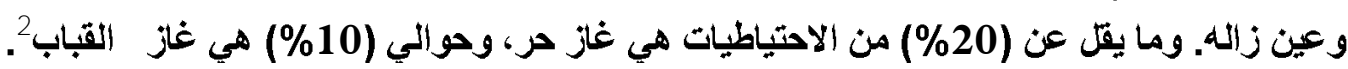

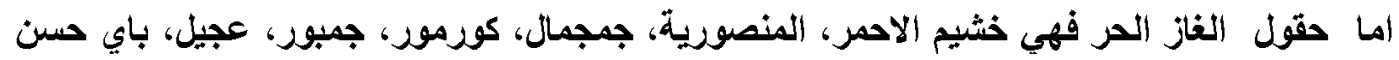

عكاز، سيبه . مانول.

واستتاداً اللى وزارة التخطيط والتعاون الانمائي، ققد حددت احتياطيات الغاز المثبت لعام 2001 نحو

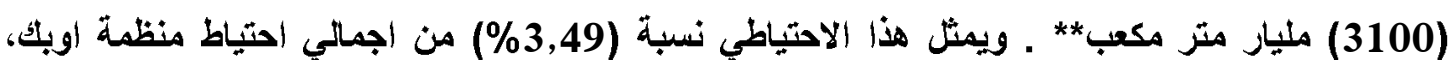

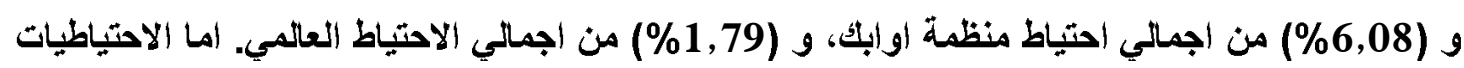

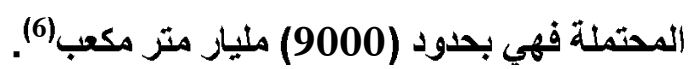

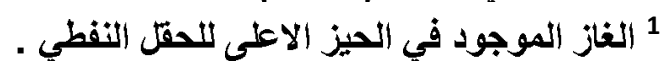

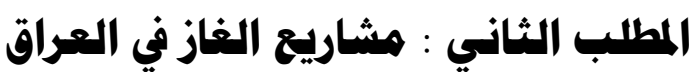

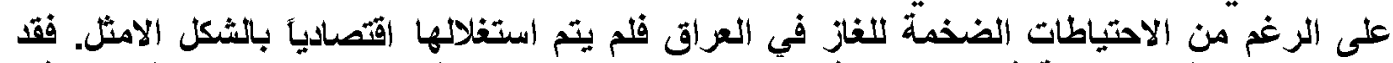

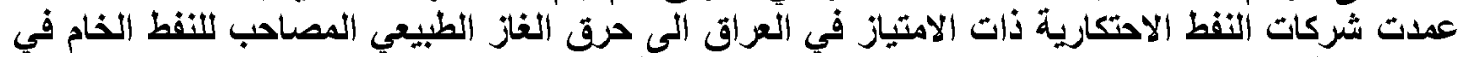

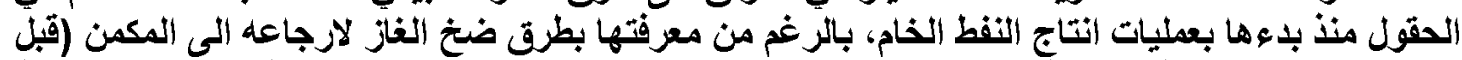

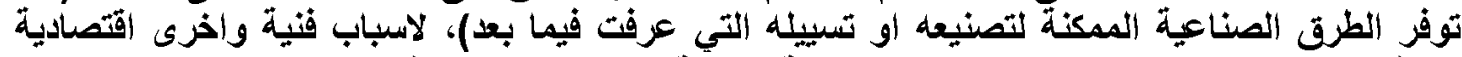

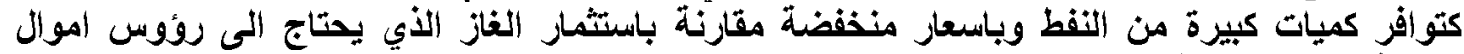

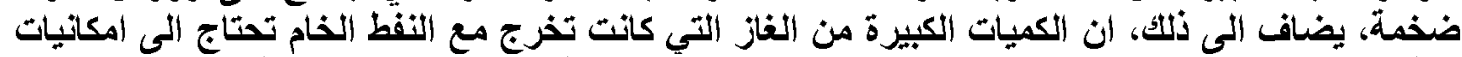

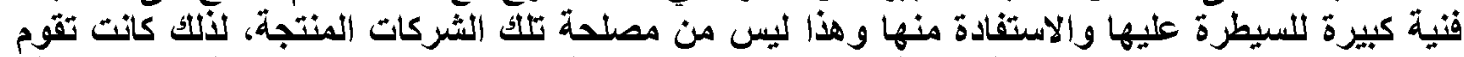

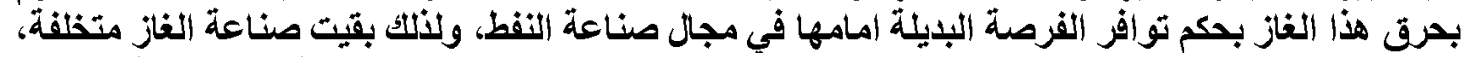

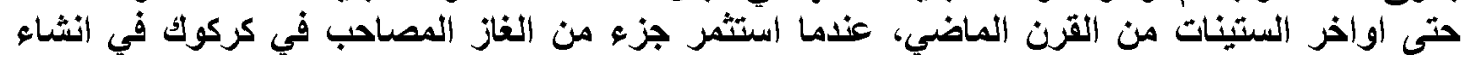

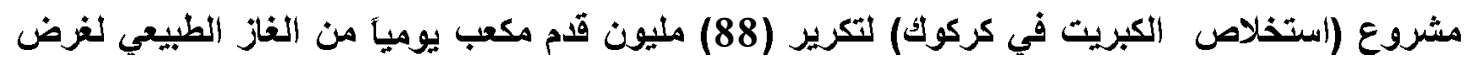

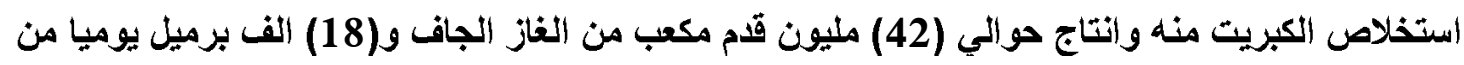

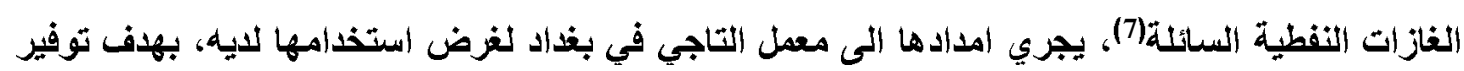


الغاز السائل للاستهلاك المحلي و الصناعي (محطة كهرباء الاورة، محطة جنوب بغذاد، معمل الاسمنت، معمل

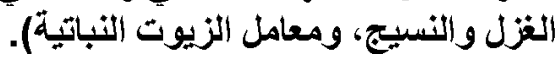
وفي عام 1977 تم بناء منثأة مماثلة في منطقة الزبيز لمعالجة الغاز الطو، وانتاج (200) مليون قدم

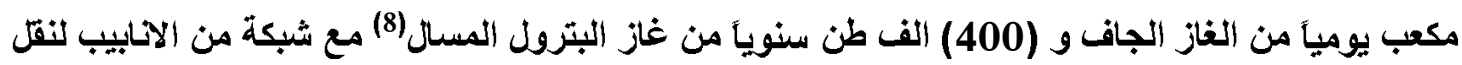

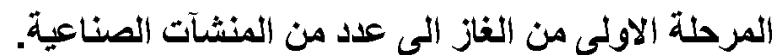

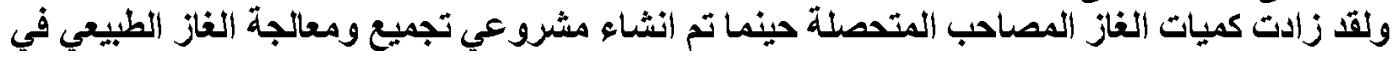

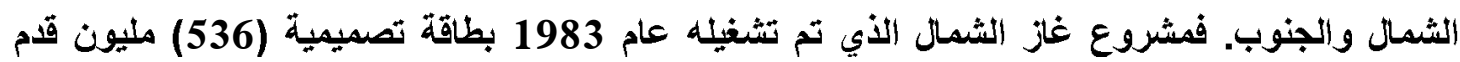

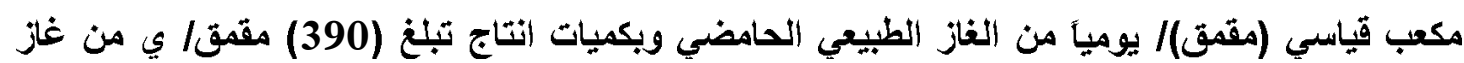
الطلو الجاف و (1100) الف طن/ السنة من الغاز السائل، و (340) الف طن/ السنة من الباتزين الطبيعي، كما هو واضح في الجدول (3). ويتضمن المجمع ثماني محطات لضغط الغاز الطبيعي ونقآه من محطات الانتاج الحقلية الى معمل الغاز

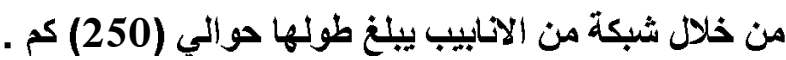

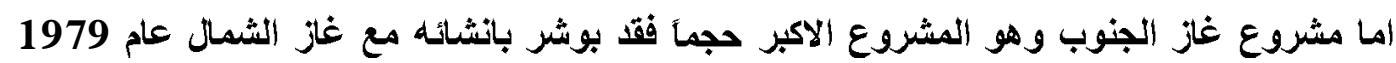

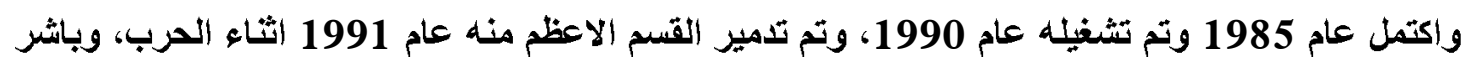
عمله من جديد في شباط 2007 بطاقات انتاج متباينة. يتكون هذا المشروع من تسع محطات كافية لتجميع

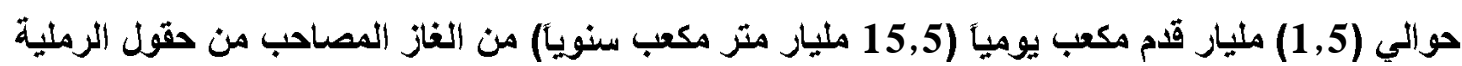

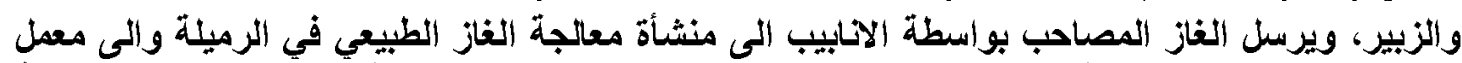

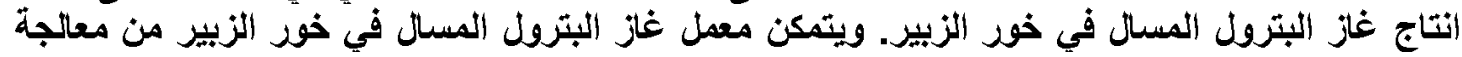

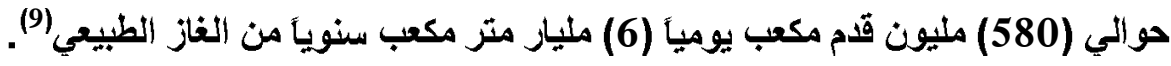
جدول (3)

الطاقات التصميمية لمنشآت تصنيع الغاز في العراق

\begin{tabular}{|c|c|c|c|c|}
\hline \multicolumn{3}{|c|}{ الأنتاج } & الطاقة (مقمق/ ي) & الموقع \\
\hline كازولين طبيعي & (الف ظن/السئة) & (مقمقائ) & & \\
\hline 340 & 1100 & 390 & 536 & غاز الشمال \\
\hline 1380 & 4000 & 760 & 1050 & غاز الجنوب \\
\hline 1720 & 5100 & 1150 & 1586 & المجموع \\
\hline
\end{tabular}

المصدر : الورقة القطرية لجمهورية العراق ، مؤتمر الطاقة العربي الثامن ، الاردن ، 2008.

$$
\text { - مقمق : مليون قدم مكعب قياسي }
$$

صمم المشروع بطاقة تصميمية تبلغ (1050) مقمقا ي. ويتتج حوالي (760) مقمقا ي من الغاز الجاف، و(400) ملايين طن سنوي من البروبان والبيوتان، وحوالي (1,4) مليون طن/ سنة من من الكازولين ويسيوق انتاج المجمع من الفاز الطبيعي الى شبكة نقل وتوزيع الغاز الجنوبية، كما يتم ضغ مزيج الطبيعي .

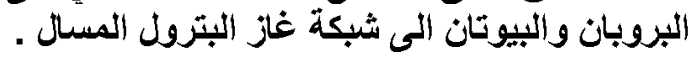


تتألف شبكة انابيب نقل الغاز الطبيعي في العراق، كما موضح في الجدول (4)، من شبكتين رئيسيتين

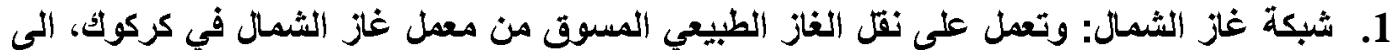

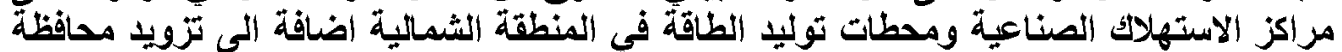

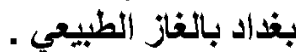

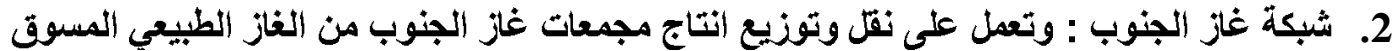

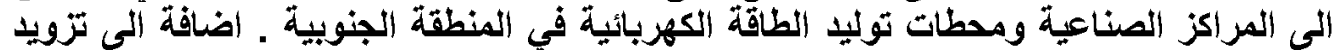

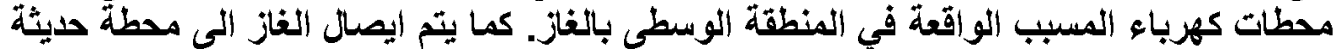

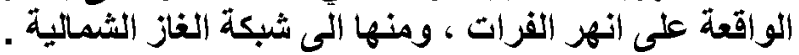

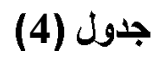

خطوط انابيب نقل وتوزيع الغاز الطبيعي الرئيسية في العراقي

\begin{tabular}{|c|c|c|c|}
\hline الطول (ك) & القطر (بوصة) & أسم الخط & $\Xi$ \\
\hline & & شبكة غاز الشمال : & i \\
\hline 88 & 24 & معمل غاز الثمال سبيجي & 1 \\
\hline 269 & 16 & عقدة بيجي ـ دصنع اسمدة اللقائم & 2 \\
\hline 170 & 18,12 & عقدة بيجي - كهرباء الموصل & 3 \\
\hline 278 & 16 & معمل غاز الثمال ـ مجمع التاجي الصناعي & 4 \\
\hline \multirow[t]{2}{*}{35} & 18 & التاجي - كهرباء جنوب بغداد & 5 \\
\hline & & شبكة الفاز الجنويبة : & ب \\
\hline 669 & 18 & محطة ضنط الفاز شمال الرميلة - حديثة & 1 \\
\hline 140 & 24 & محطة ضفط الفاز شمال الرميلة ـ كهرياء الناصرية & 2 \\
\hline 290 & 42 & الناصرية - كهرباء المسيب & 3 \\
\hline 55 & 42 & شمال الزميلة ـ معمل خور الزبيز & 4 \\
\hline 48 & 24 & خوز الزبير - كهرباء الحارثة & 5 \\
\hline 18 & 40,30 & خوز الزيبيز - مصنع اسمدة الزبيز & 6 \\
\hline 10 & 10 & خور الزيبر - كهرياء الثعيبة & 7 \\
\hline 5 & 20 & خور الزبير - مصنع البتروكيمياويات & 8 \\
\hline
\end{tabular}

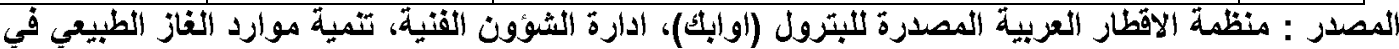
الدول العربية، الكويت، 2009، جدول (7-3) . 


\section{هشروع تصدير الغاز العراتي إلى الكويت}

أنشئ المشروع بارية عام 1986 لتصدير الغاز الطبيعي المصاحب والمنتج من حقول الرميلة وتوزعت

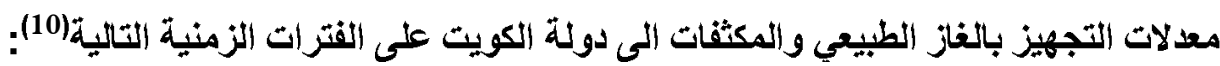
1. المدة (1987-1986) : حيث تم في هذه المرحلة تجهيز (2,40-2,04) مليون متر مكعب يوميا

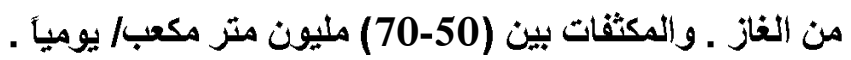

2. في المرحلة الثانية تم تجهيز (5,66-4,25) مليون متز مكب/ يومياً، والمكثفات (200-600)

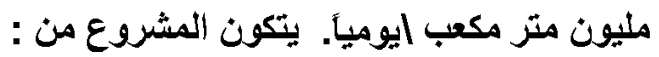

أ. انبوب لنقل الغاز بقطر (36-32) بوصة، يمتد من شمال الزميلة الى محطة بي اس 130

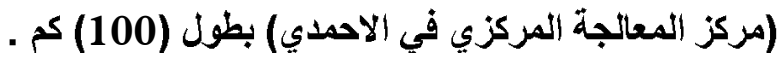

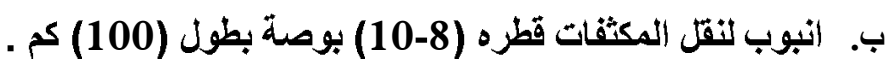

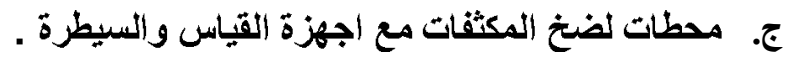

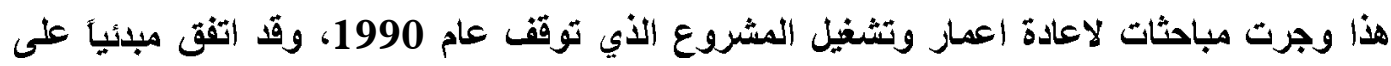

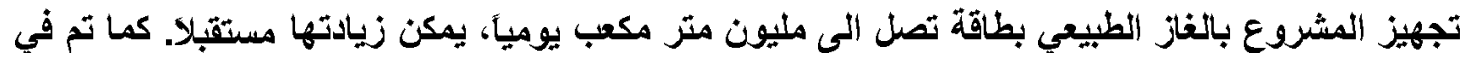

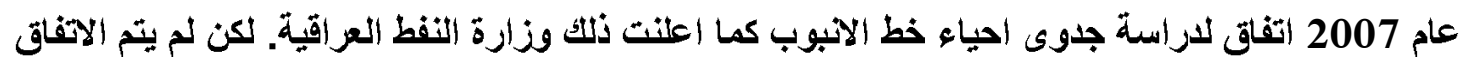
النهائي على ذلك لعدم وجود ثقة بين الجانبين،رغم حاجة الكويت الى الغاز واستيراده من قطر اول محاولة استير اده من ايران . 


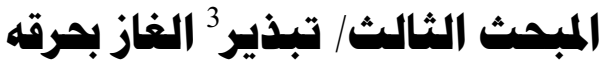

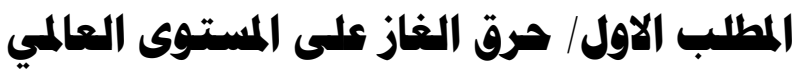

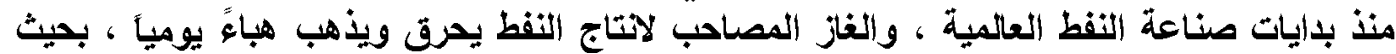

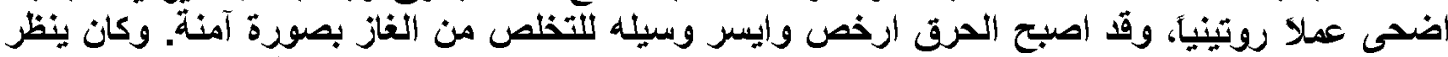

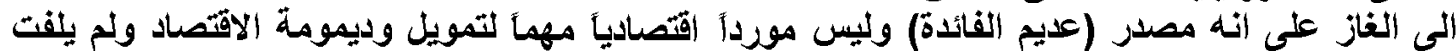

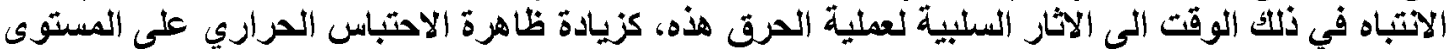

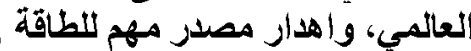

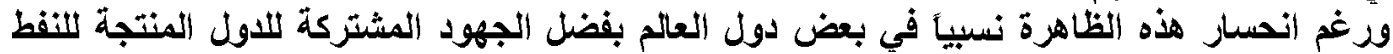

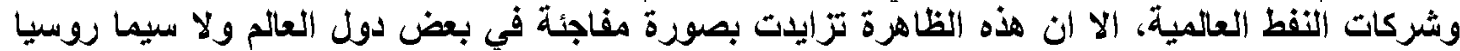

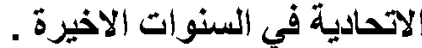

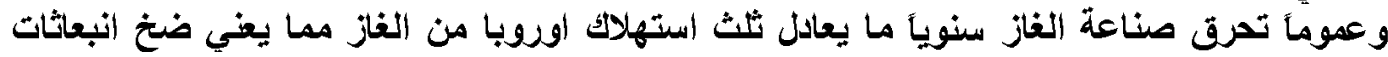

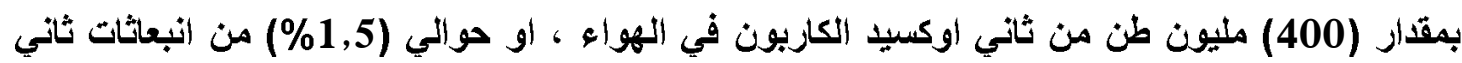
اوكسيد الكاريون على المستوى العالمي(11)، وهو بذلكف يمثل مشكلة بيئية كبيرة .

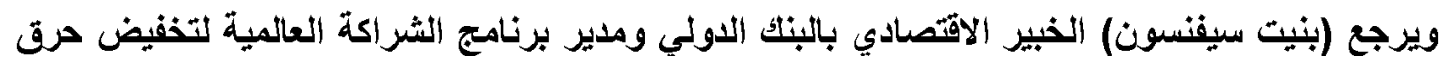

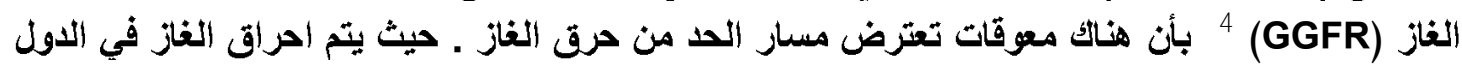

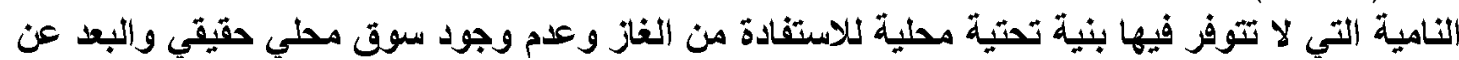

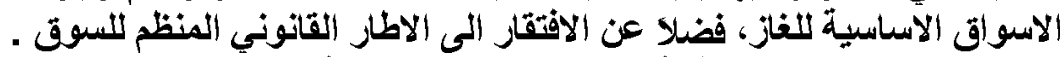

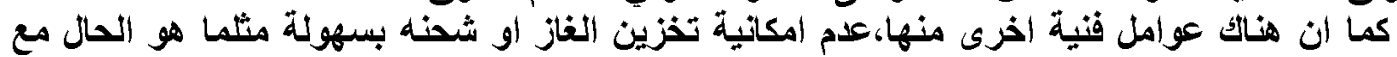

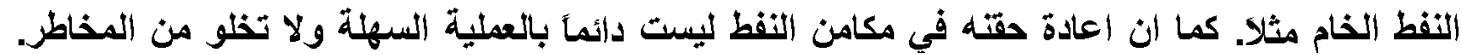

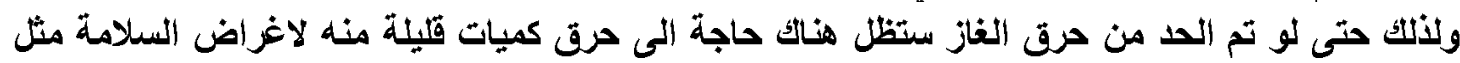

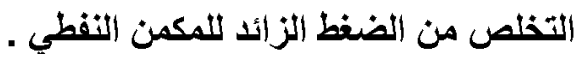

3 ألتبذير في عم الاقتصاد هو خسارة يمكن تلافيها ، اذا كاتت تكاليف تلافي الخسارة اقل من قيمتها السوقية الحالية او المستقبلية

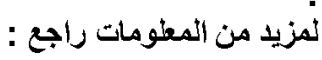

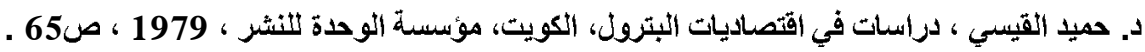
4 الثراكة العالمية لتخفيض حرق الغاز التابعة للبنث الاوني (GGFR) هي عبارة عن شراكة بين القطاعين العام والخاص تأستست

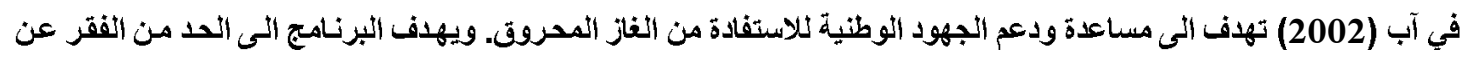

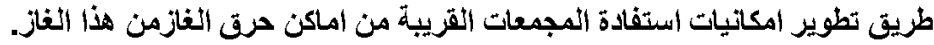
انظر : (1) منظمة اوابك ، ندوة صناعة الناز الطبيعي: الحاضر والمستقبل (2008/6/19-17 باريس)، مجلة النفظو التعاون

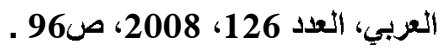


والجدول (5) يبين اكبر (20) دولة عالميا في حرق الغاز للمدة (2005-2009) ومنه يتضح:

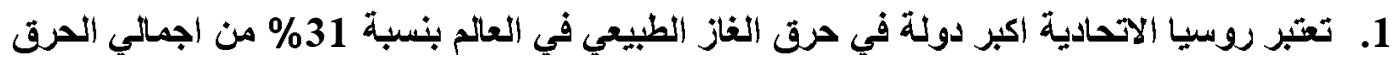

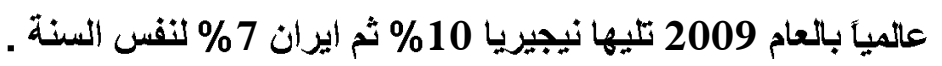

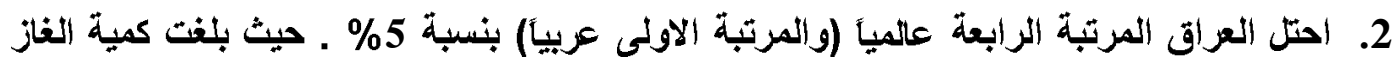
المحروقة 8,1 مليار متر مكعب لسنة 2009 بزيادة مقار ها مليار متر مكعب عن العام السابق .

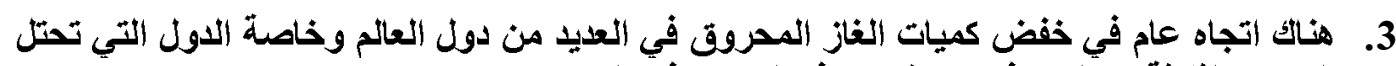

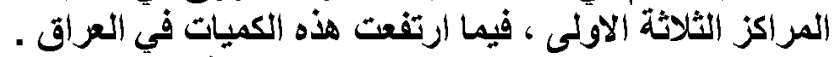

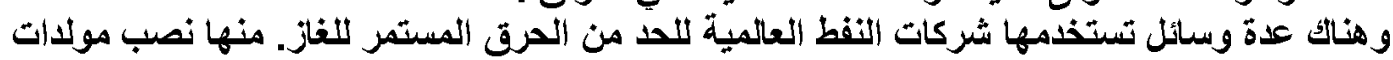

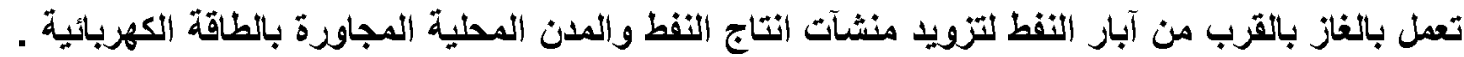

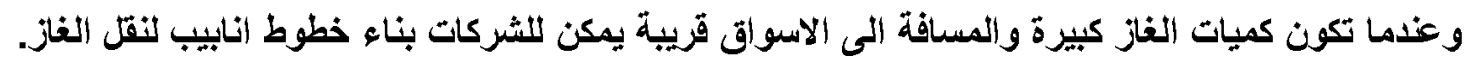

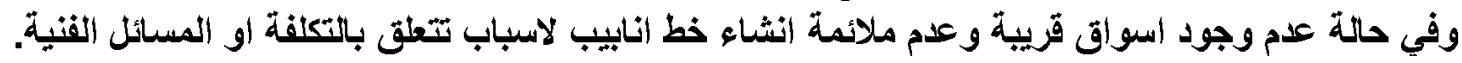

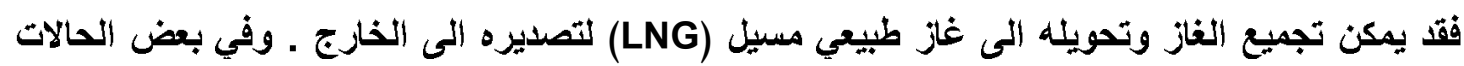

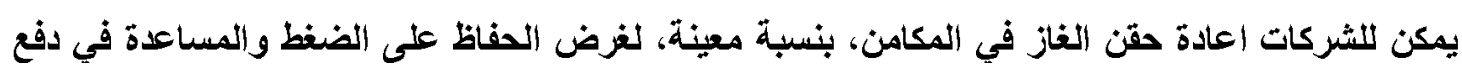
المزيد من النفط الى خارج المكمن التفطي . 
جدول (5) أكبر 20 دولة عالميا في حرق الغاز الطبيعي (2005-2009) بليون متر مكب

\begin{tabular}{|c|c|c|c|c|c|c|}
\hline 2009 & 2008 & 2007 & 2006 & 2005 & الألدية & $ت$ \\
\hline 46.6 & 42.2 & 52.3 & 50.0 & 58.3 & ل روسيا & -1 \\
\hline 14.9 & 15.5 & 16.3 & 18.6 & 21.3 & نيجيريا & -2 \\
\hline 10.9 & 10.9 & 10.7 & 12.23 & 11.7 & ايران & -3 \\
\hline 8.1 & 7.1 & 7.6 & 7.2 & 7.0 & العزاق & -4 \\
\hline 5.0 & 5.4 & 5.5 & 6.2 & 6.2 & كازخستان & -5 \\
\hline 4.9 & 6.2 & 5.6 & 6.4 & 5.7 & الجزائر & -6 \\
\hline 4.0 & 4.0 & 2.8 & 2.8 & 2.8 & الولايات ألمتحدة الامريكية & -7 \\
\hline 3.5 & 3.8 & 3.8 & 3.7 & 3.4 & التسعودية & -8 \\
\hline 3.5 & 4.0 & 3.8 & 4.4 & 4.6 & ليييا & -9 \\
\hline 3.4 & 3.5 & 3.5 & 4.0 & 4.7 & أنجولا & -10 \\
\hline 3.9 & 3.6 & 2.7 & 2.1 & 1.9 & مكسيك & -11 \\
\hline 2.8 & 2.7 & 2.2 & 2.1 & 2.2 & فنزويلا & -12 \\
\hline 2.5 & 2.5 & 2.6 & 3.2 & 3.0 & أندونيسيا & -13 \\
\hline 2.4 & 2.5 & 2.6 & 2.9 & 3.0 & الصين & -14 \\
\hline 2.2 & 2.3 & 2.4 & 2.3 & 2.3 & قطر & -15 \\
\hline 1.9 & 2.0 & 2.0 & 2.3 & 2.6 & عمان & -16 \\
\hline 1.8 & 1.9 & 2.0 & 1.7 & 1.3 & كندا & -17 \\
\hline 1.8 & 1.6 & 1.5 & 1.7 & 1.7 & مصر & -18 \\
\hline 1.8 & 2.0 & 2.2 & 2.5 & 2.5 & الكويت & -19 \\
\hline 1.7 & 2.7 & 2.1 & 2.9 & 2.7 & ازيكستان & -20 \\
\hline 127 & 126 & 133 & 139 & 149 & & المجمو \\
\hline 20 & 20 & 21 & 22 & 23 & & بقية دو \\
\hline 147 & 146 & 154 & 162 & 172 & \multicolumn{2}{|c|}{ اجمالي الغاز المحروق } \\
\hline & & & & & \multicolumn{2}{|c|}{ 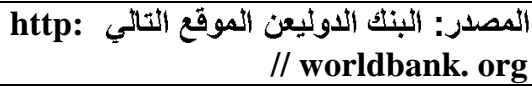 } \\
\hline
\end{tabular}




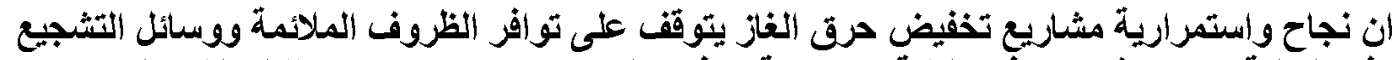

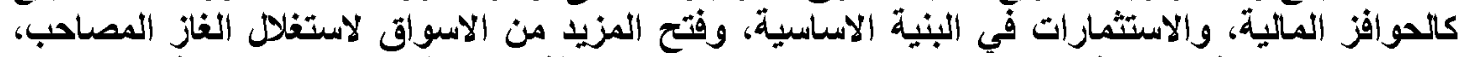

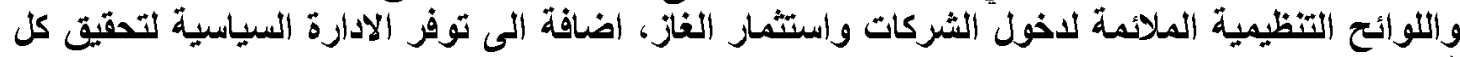

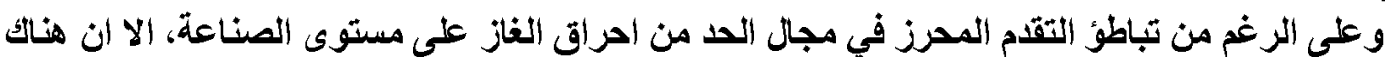

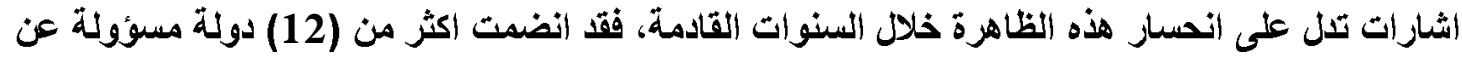

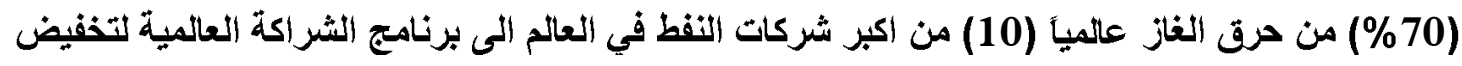

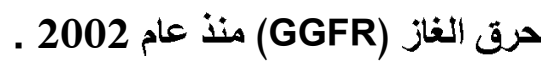

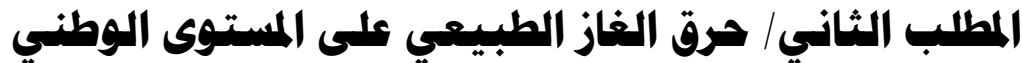

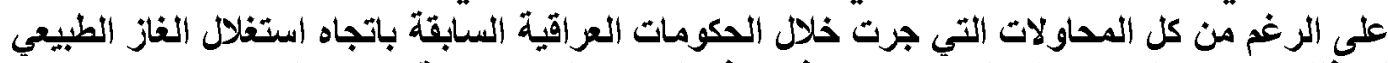

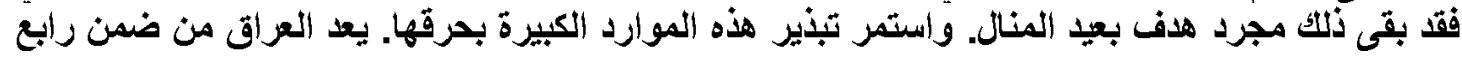

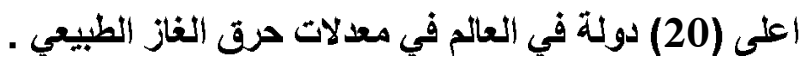
وقد دعت الثراكة العالمية لتخفيض حرق الثفاز التابعة للبنك الدولي (GGFR) الحكومة العراقية

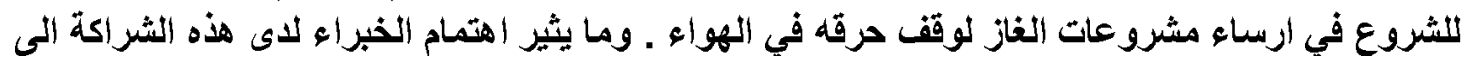

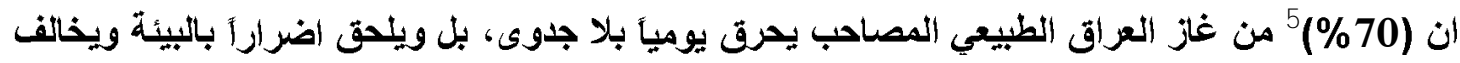

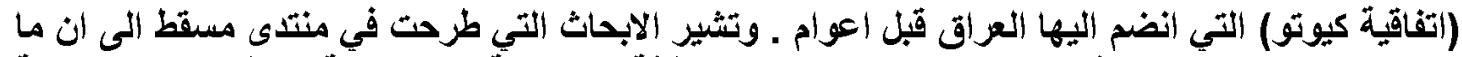

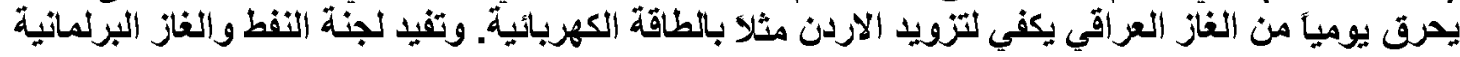

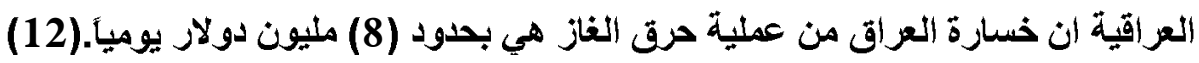
والجدول (6) يبين كمية الغاز الطبيعي المنتج والمستهلك والمحروق للفترة (1985-2008) ونسب المبن

1. ان نسبة الغاز المحروق كانت 44\% للفترة (1985-1989) انخفضت اللى (16\%) للفترة (90)

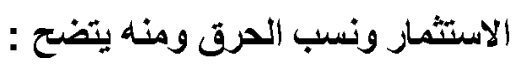

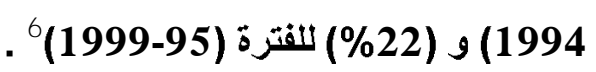

2. عادت نسبة الغاز المحروق للارتفاع مجداً خاصة بعد الاحتلال الامريكي للعراق لتبلغ حوالي

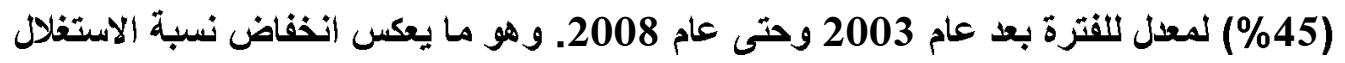
وزيادة الهـر في الغاز الطبيعي . 3. نلاحظ انخفاض كميات الغاز المنتجة والمستهلكة بعد الاحتلال عام 2003 مقارنة بالسنوات التي قبلها، ولكنها عادت للارتفاع مجداً منذ عام 2006*، ولكن جاء ذلك مترافقا مع تزايد معدلات

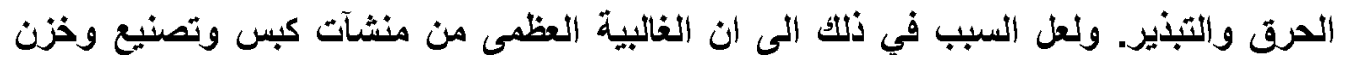

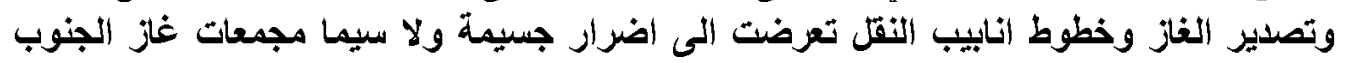

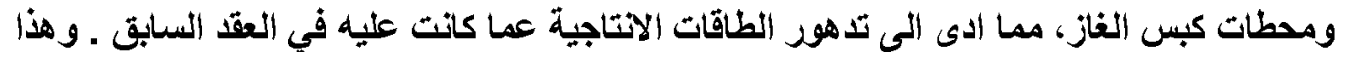

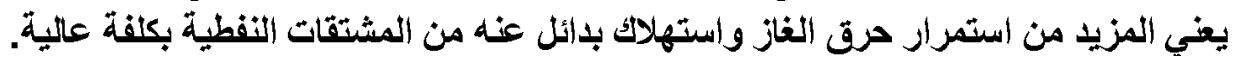

5 هذه النسبة تتناقض مع الاحصائيات الرسمية الصادرة عن الجهاز المركزي للاحصاء التي تقدر بحوالي 46\% للفترة (2005-

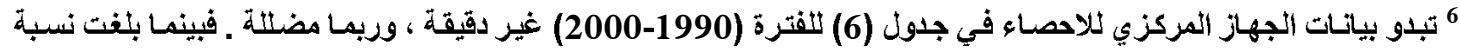

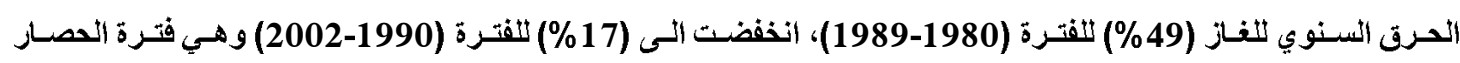

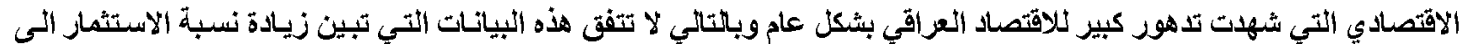

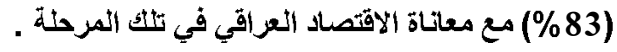


جدول رقم (6)

كية الفاز الطييع المنتج والمستهلك و المحروق في العراق للسنوات (1985-2008) (مليون متر مكب قياسي)

\begin{tabular}{|c|c|c|c|c|c|}
\hline 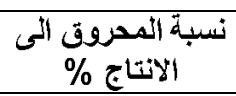 & المحروق (3) & نالاستغلالاستثمار & المستهلث (2) & المنتج (1) & السنة \\
\hline 44 & 24959 & 46 & 26307 & 56668 & 1989-85 \\
\hline 16 & 5926 & 84 & 31997 & 37928 & $1994-90$ \\
\hline 22 & 11597 & 78 & 42340 & 53939 & 1999-95 \\
\hline 32,1 & 4519 & 68,9 & 10020 & 14539 & 2000 \\
\hline 29,00 & 4271 & 71,00 & 10448 & 14719 & 2001 \\
\hline 24,3 & 3340 & 75,7 & 10415 & 13755 & 2002 \\
\hline 43,00 & 4239 & 57,00 & 5542 & 9781 & 2003 \\
\hline 49,00 & 6958 & 51,00 & 7212 & 14171 & 2004 \\
\hline 48,00 & 6611 & 52,00 & 7077 & 13723 & 2005 \\
\hline 46,7 & 81964 & 53,3 & 93545 & 175509 & 2006 \\
\hline 48,00 & 80417 & 52,00 & 87118 & 167535 & 2007 \\
\hline 40,9 & 6072,8 & 59,1 & 8776,2 & 14848 & 2008 \\
\hline
\end{tabular}

المصدر: الجدول من تتظيم الباحث بالاعتماد على وزارة التخطيط وتكنولوجيا المعلومات، الجهاز المركزي للاحصاء،

*أنخفت كميات الغاز المنتجة عام (2008) بسبب تردي الاوضاع السياسية والامنية في جنوب العراق.

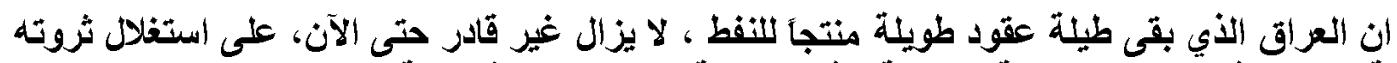

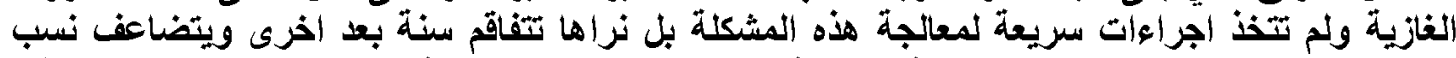

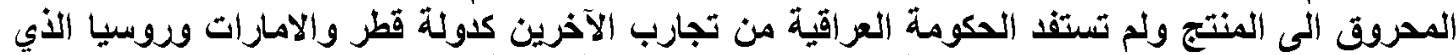

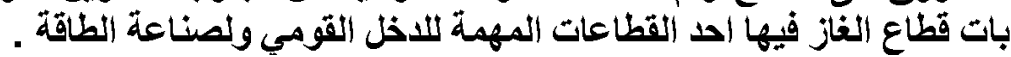

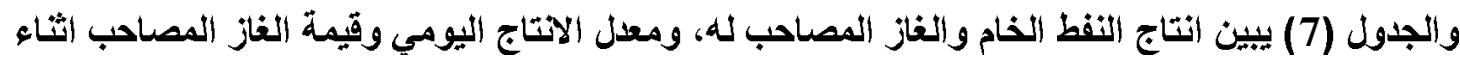
الفترة (2008-2000) ومنه يتضح : 1. بلغ معدل انتاج الغاز الطبيعي، وكله غاز مصاحب، اثناء المدة اعلاه ، (1112) مليار قمق/سنوي،

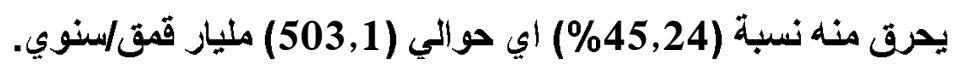

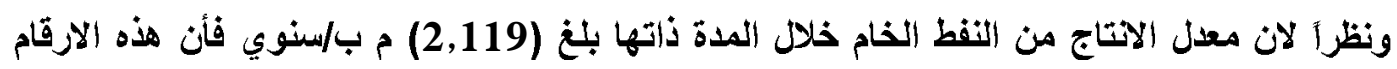

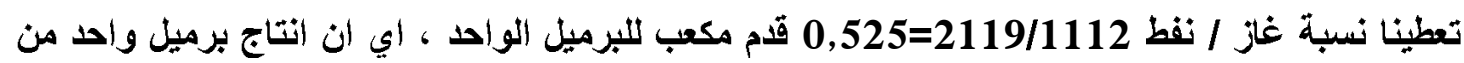

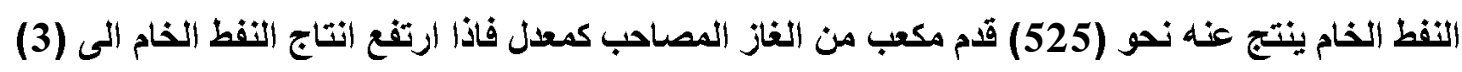

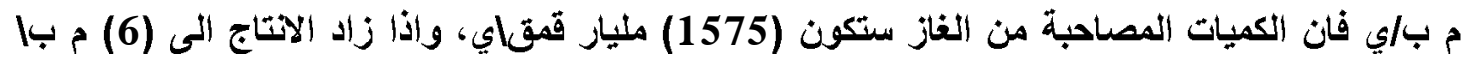

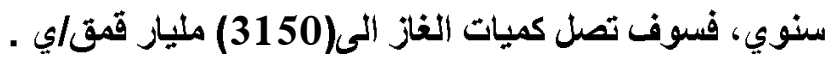


وكما تبين من جولتي التراخيص الاولى والثانية للحقول النفطية المنتجة ـ والحقول النفية المكتشفة

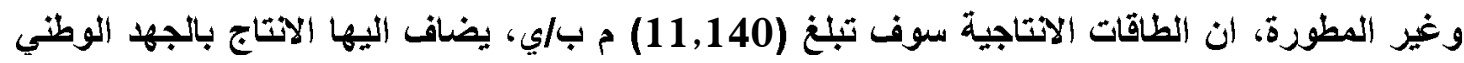
والبالغ بحدود مليون م باي. يكون مجموع الطاقات الاتتاجية المتاحة في عام 2016/2015 نحو

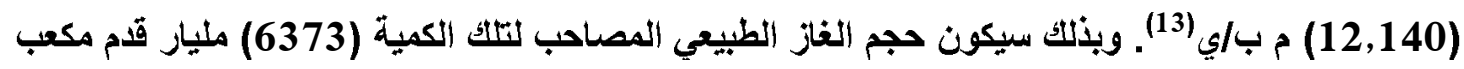

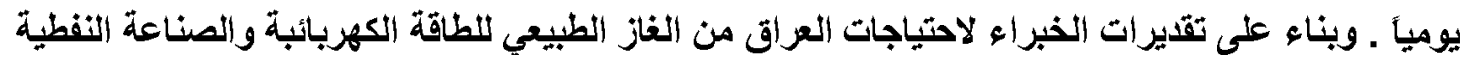

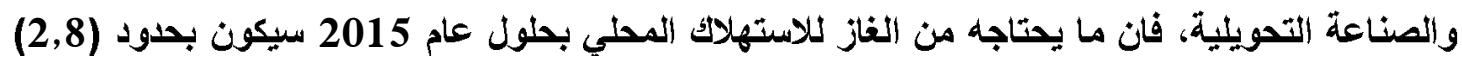

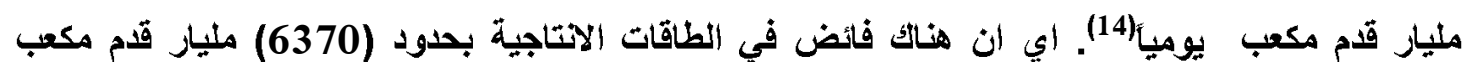

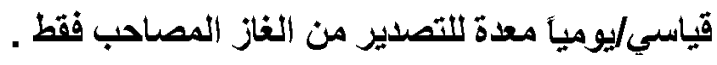
2. بلغت قيمة الغاز المصاحب للمدة ذاتها (42936) مليون دولار، اي بمعل سنوي (4771) مليون

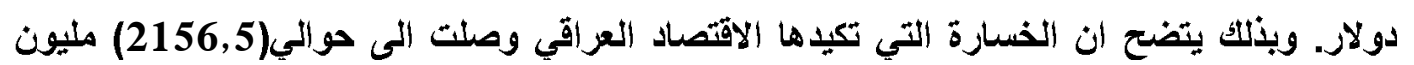

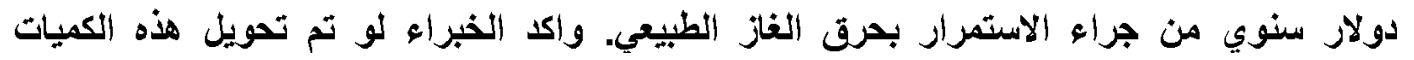

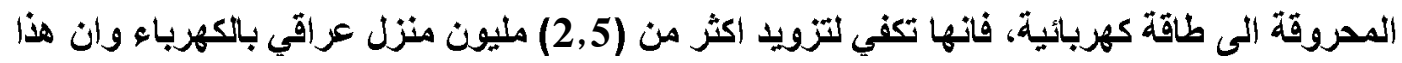

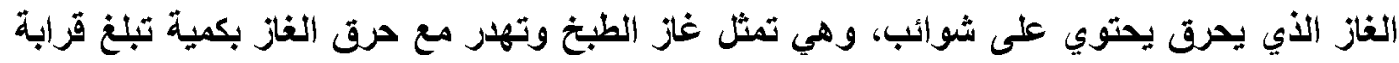

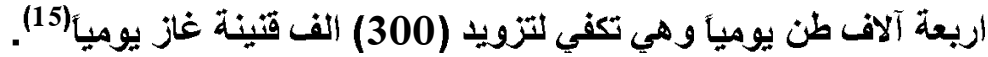

\section{جدول (7)}

انتاج النفط الخام والغاز المصاحب له ومعدل الانتاج اليومي وقيمة الغاز المصاحب (2000-2008)

\begin{tabular}{|c|c|c|c|c|c|c|c|c|c|}
\hline \multicolumn{9}{|c|}{ السنة } & \multirow{2}{*}{ التفاصيل } \\
\hline 2008 & 2007 & 2006 & 2005 & 2004 & 2003 & 2002 & 2001 & 2000 & \\
\hline 834677 & 742890 & 713594 & 676423 & 730294 & 560588 & 812799 & 943760 & 952049 & اجمائي أنتاج برميل) الخام \\
\hline 2281 & 2036 & 1955 & 1853 & 1995 & 1536 & 2227 & 2586 & 2601 & 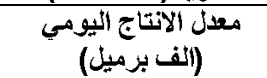 \\
\hline 457054 & 431570 & 422260 & 398736 & 409106 & 283592 & 382512 & 429286 & 439357 & اجمالي الفاز المصناحباً \\
\hline 1252 & 1182 & 1157 & 1092 & 1121 & 777 & 1048 & 1170 & 1204 & (مليار قدم مكب قالاتتاج اليومسي) \\
\hline 9141 & 6474 & 4223 & 3987 & 4091 & 2836 & 3825 & 4293 & 4066 & قيمة الثناز المصاحب) \\
\hline
\end{tabular}

ملاحظة : تم زيادة سعر الثاز المصاحب خلال عام 2000 ولم يتثيز السعز التى عام 2004 اعثبه بعد ذلك زيادات

سنوية لاحقة.

المصدر : وزارة النفط ، قسم البحوث والاراسات ، 2009 . 


\section{المبحث الرابع/ الآفاق المستقبلية لصناعة الغاز الطبيعي في العراق}

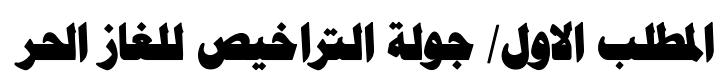

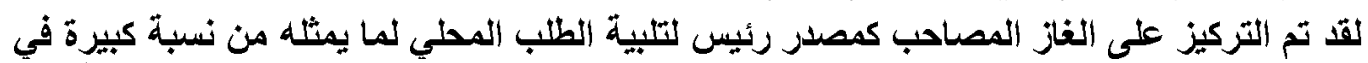

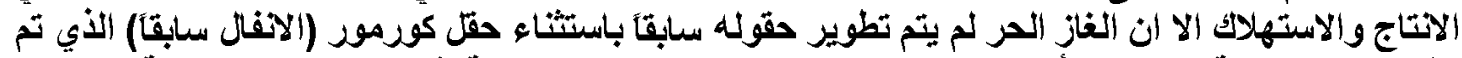

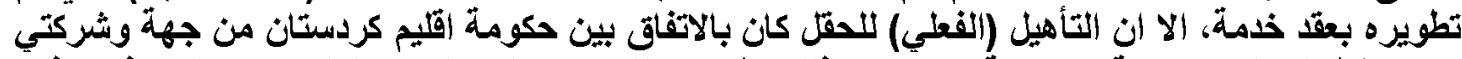

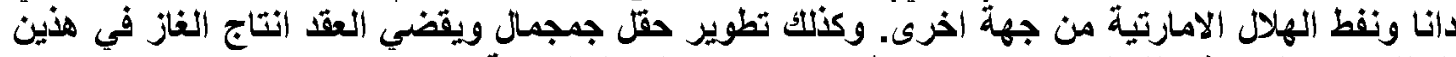

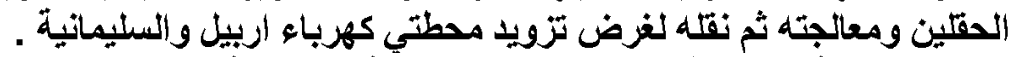

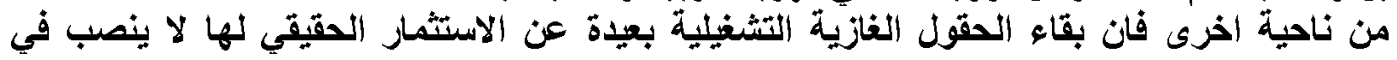

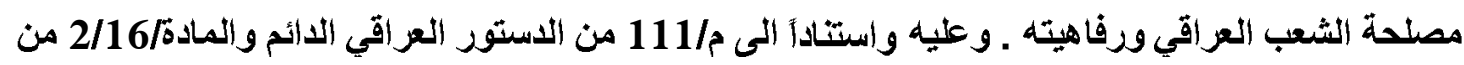
مشروع قانون النفط والغاز الاتحادي الصادر في حزيران 2007 (الخاص بالتراخيص) فته انجزت وزئه وزارة النفط جولة تراخيص ثالثة خاصة بالحقول الغازية7 ويعقود خدمة ( Contract Service Risk) حيث تقوم

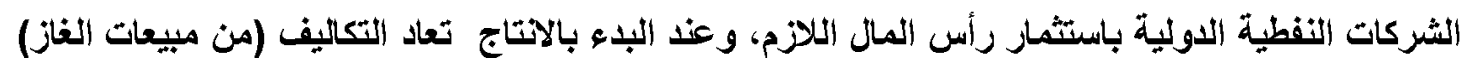

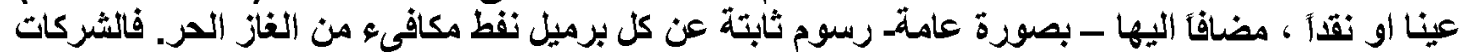

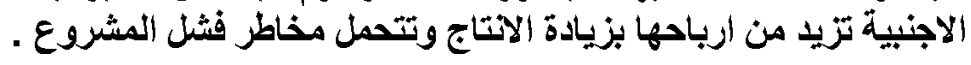

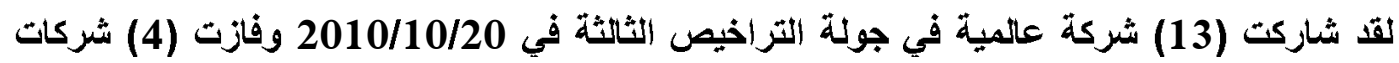

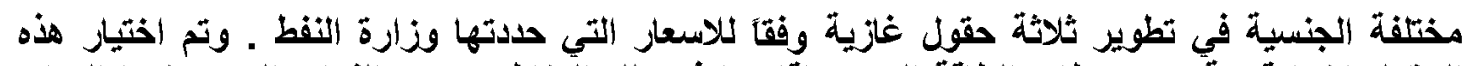

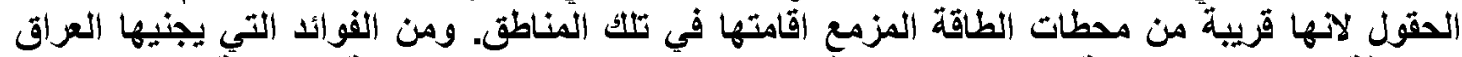

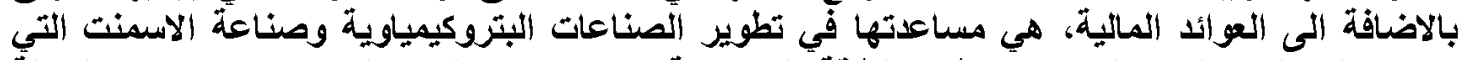

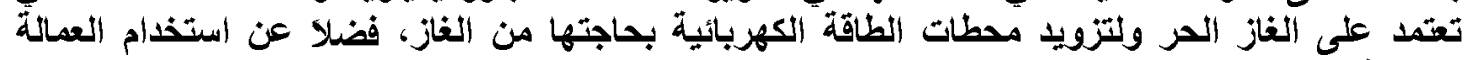

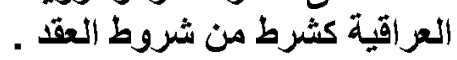

والجدول (8) يبين حقول جولة التر اخيص الثالثة للحقول الغازية ومنها يتضح :

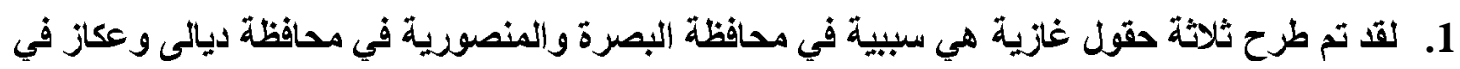

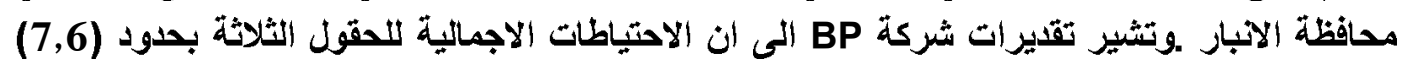
تريليون قدم مكعب من الغاز الجاف ، وتمثل نسبة (16,8) من احتياطي الغاز الطبيعي البالغ (112)

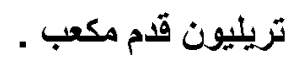

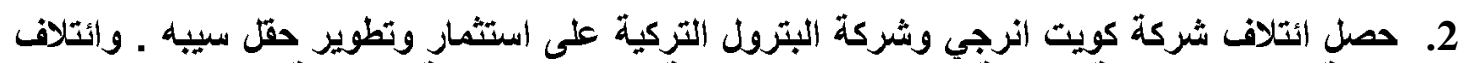

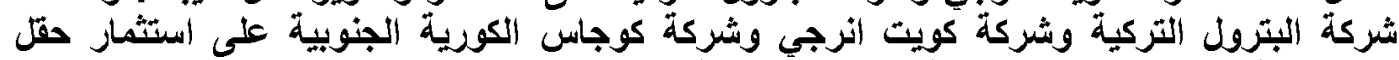

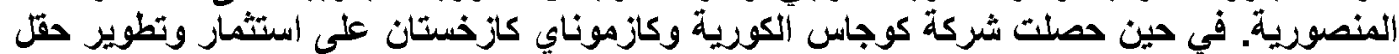
عكاز.

و هناك تقديرات اخرى للاحتياطيات الاجمالية للحقول الثلاثة تتجاوز (11) تريليون قدم مكب من الغاز(16).

7 تم طرح حقلين هما عكاز والمنصورية في جولة التراخيص الاولى ، لحقول النقط الخام المنتجة ، في ت2008 ولم يتم التعاقد لاستثمار ها. 
جدول (8) جولة التراخيص الثاثثة لحقول الغاز الحر (2010/2/20)

\begin{tabular}{|c|c|c|c|c|c|c|}
\hline ترائيون متربي & قدم مكعب من الختاز & 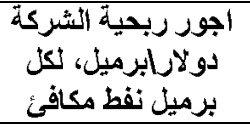 & المشاركة & اسم الثشركة & المحافظة & اسم الحقل \\
\hline 0,1 & 100 & 7,5 & $\begin{array}{l}\% 60 \\
\% 40\end{array}$ & - مشثل الحمثل) - مويت انرجي & البصرة & سيبة \\
\hline $\mathbf{3 , 0 0}$ & 320 & 7,00 & $\begin{array}{l}\% 50 \\
\% 30 \\
\% 20\end{array}$ & 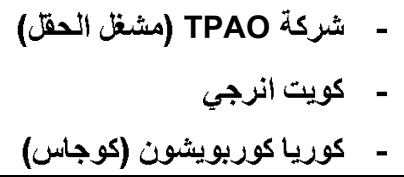 & ديالى & المنصورية \\
\hline 4,5 & & 5,5 & $\begin{array}{l}\% 15 \\
\% 85\end{array}$ & شازخستان كوجاس الكورية كازموناي & الانبار & عكاز \\
\hline
\end{tabular}

المصدر : الجدول من عمل الباحث بالاستتاد الى : معلومات من الموقع الاككتروني لوزارة النفط العر اقية .

BP. Statical Review of World Energy. 2009

الاحتياطي عن : (1)

3- وقد تم تقييم المناقصات على اجور ربحية الثركة بالدولار الامريكي لكل برميل نفط مكافئ وعلى حجم الاتتاج

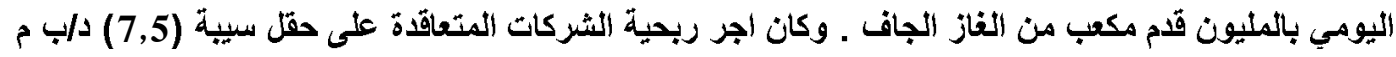

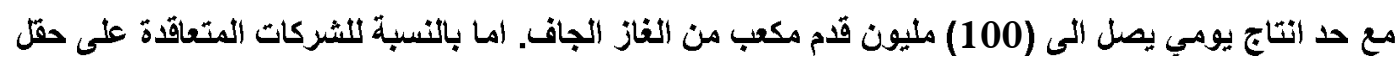

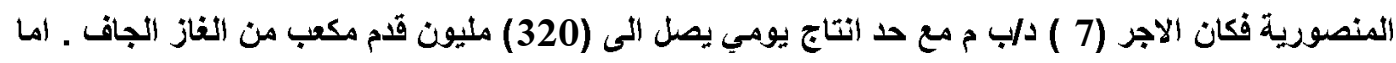

حقل عكاز فكان معدل اجر (5,5) دولار عن كل برميل نقط مكافئ ينتج .

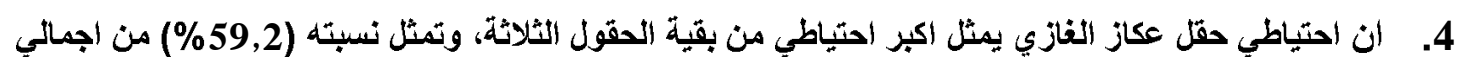

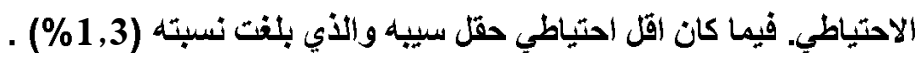

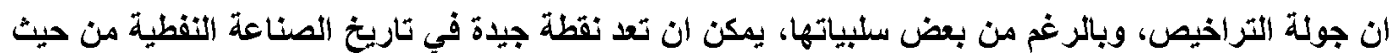

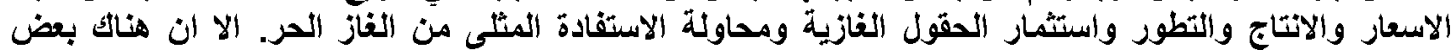

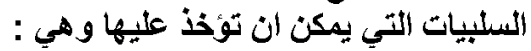

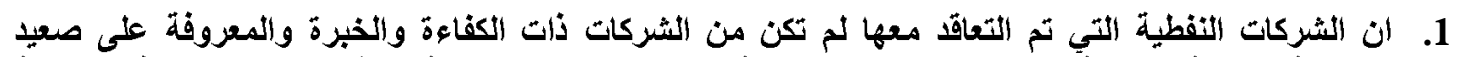

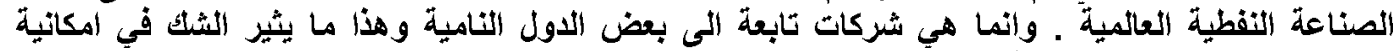

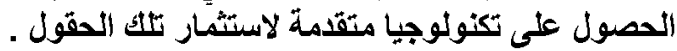

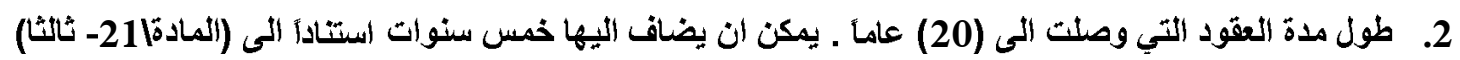

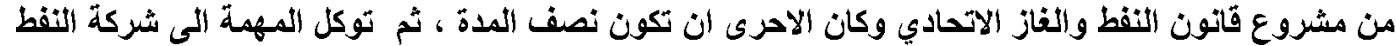

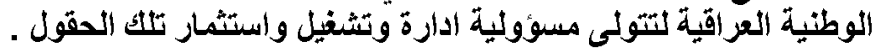

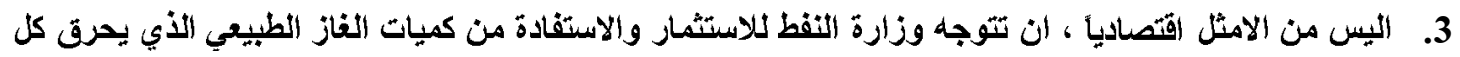

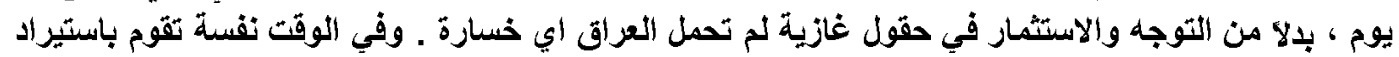

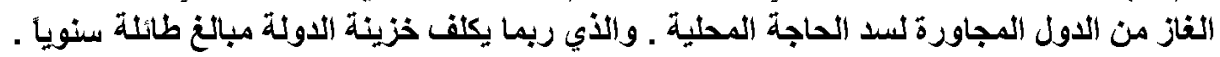

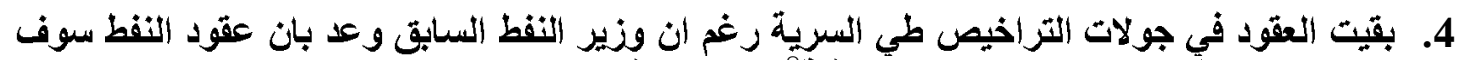

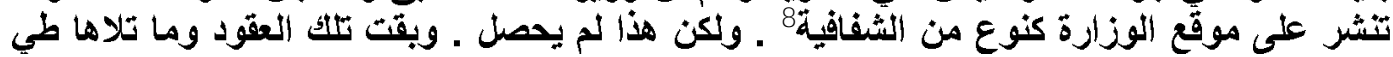

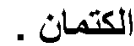

8 تصريح وزير النفط العراقي حسين الثهرستاني في ندوة الآفاق المستقبلية لصناعة النفط في العراق التي اقيمت في

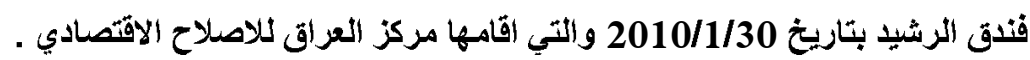




\section{المطاب الثاني/ هشروع استثمار غاز الجنوب}

في ايلول 2008 تم اتفاق مبئي بين شركة نفط الجنوب العراقية وشركة شل Royal Dutch) الهولندية، لمدة سنة واحدة ثم تجدلد ستة اشهر اخرى لتأسيس شركة عراقية اجنبية مشتركة ـ تكون مكونة اسههها (51\%) للثركة العراقية و (49\%) لثركة شل. ويعد توقيع العقد النهائي تكون مدة العقد (20) سنة يمكن زيادتها (خمس) سنوات (خرى بموافقة الطرفين ـ ويشمل هذا الاحفاق نسبة (83\%) من

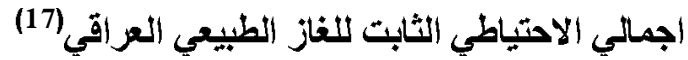

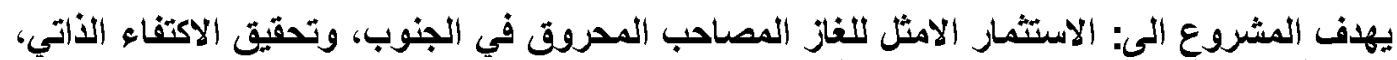

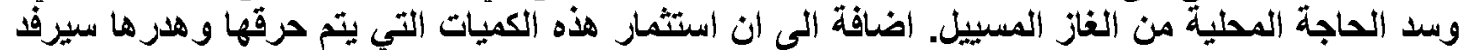

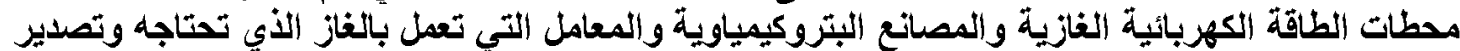

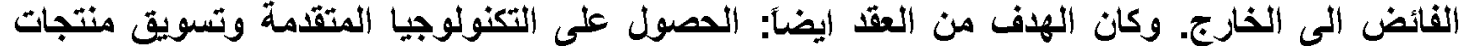

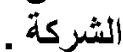

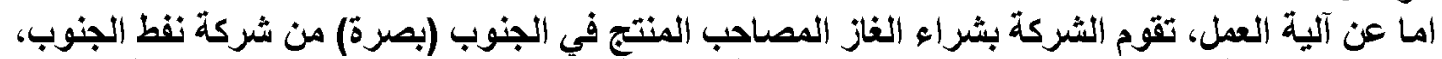

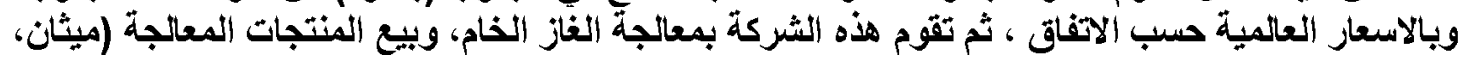

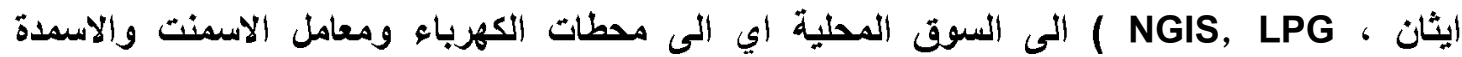

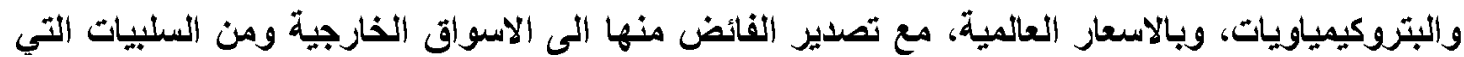
تؤخذ على هذا الاتفاق :

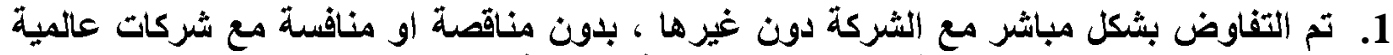

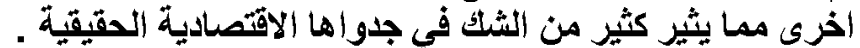

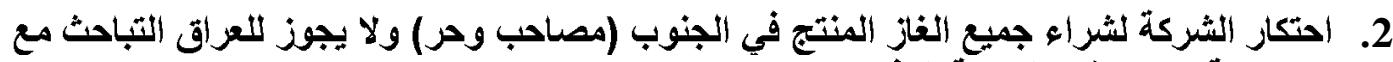

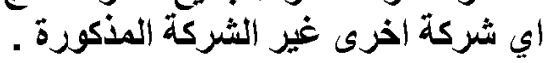

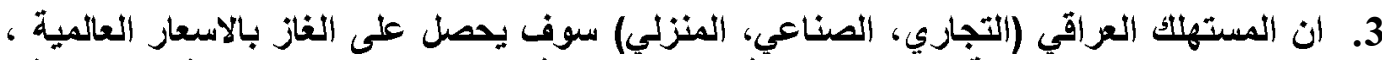

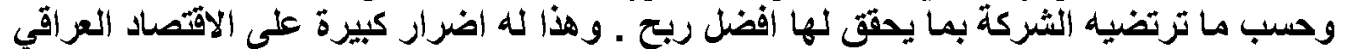

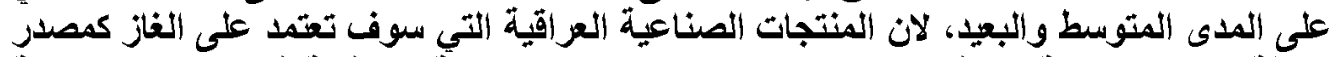

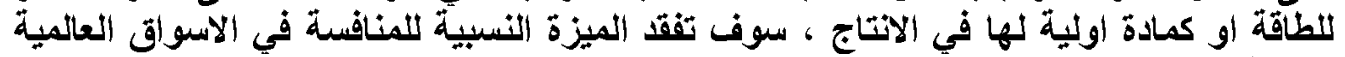

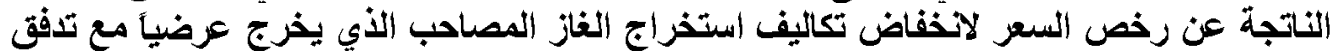

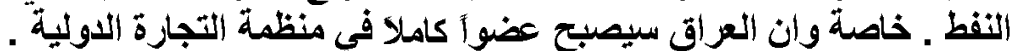

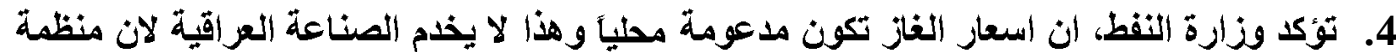

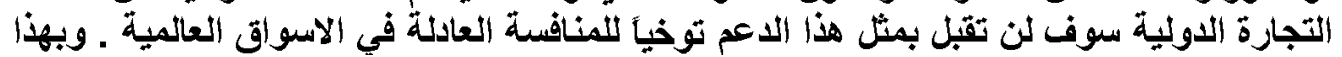

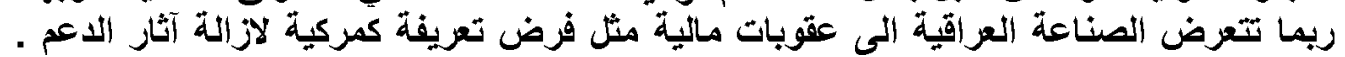

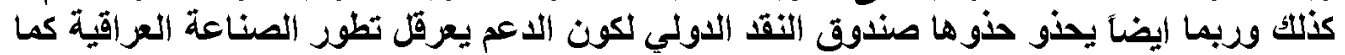

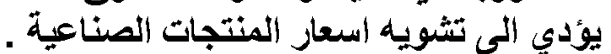

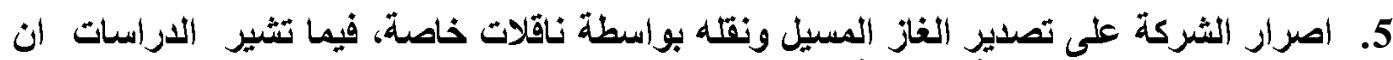

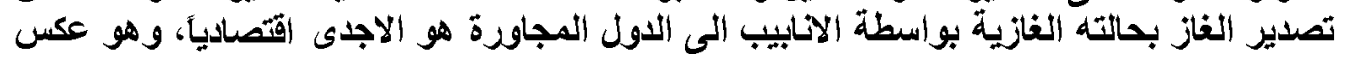

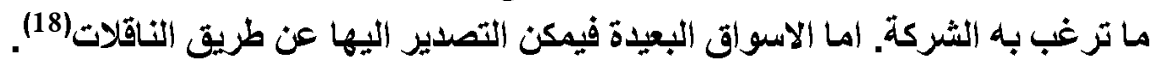

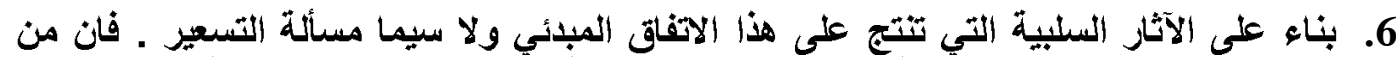

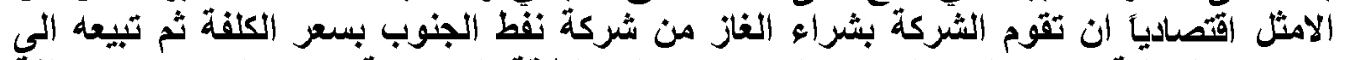

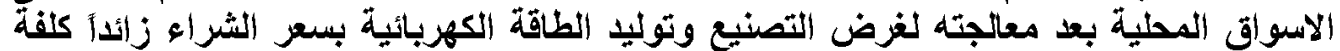

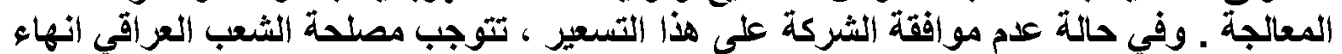

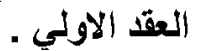




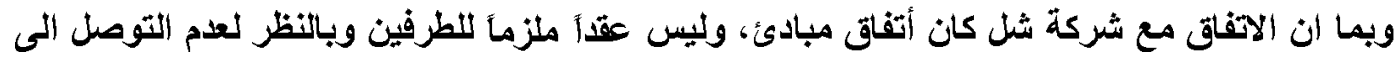

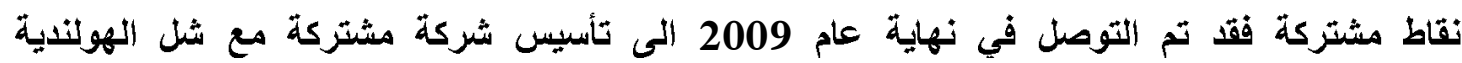

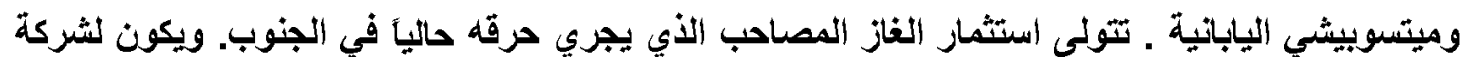

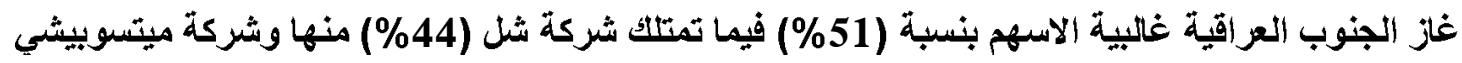
(5\%). وستثولى الثركة تجميع الغاز الخام المصاحب ومعالجته، ويتم تسويقه والمنتجات المصاحبة له من النه

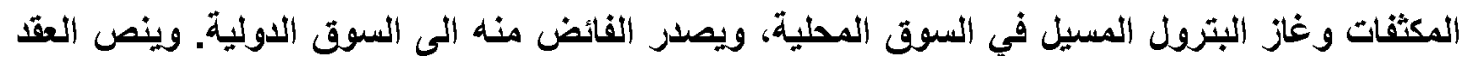

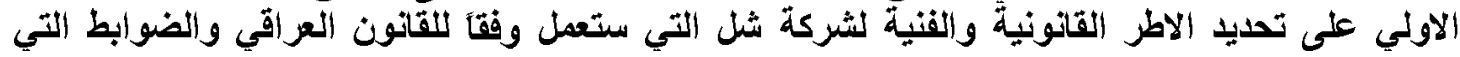

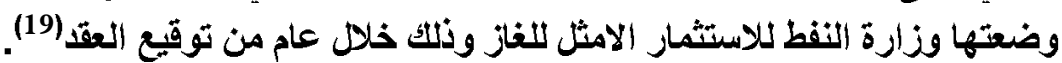

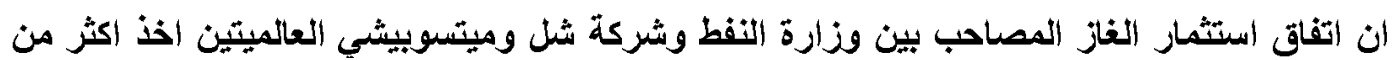

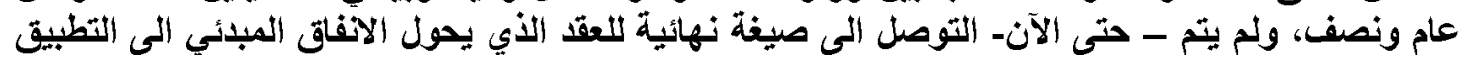

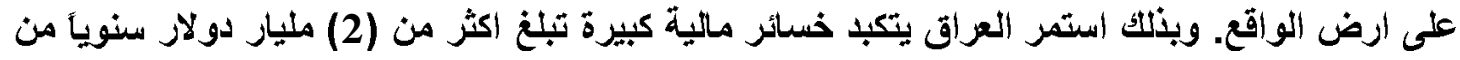

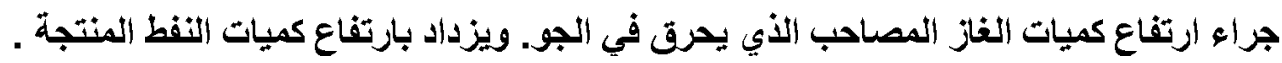

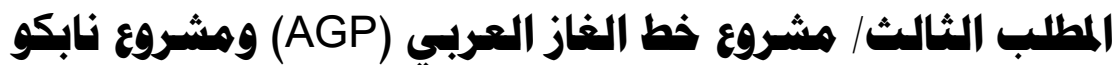

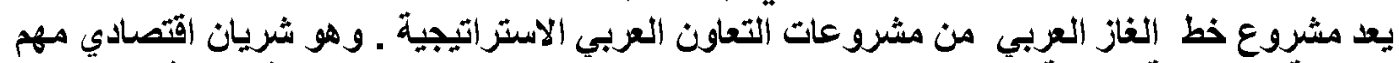

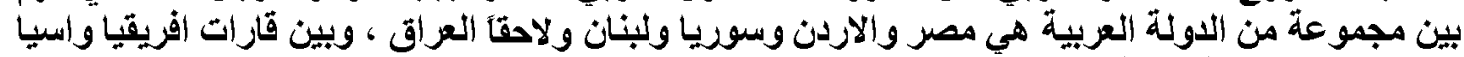

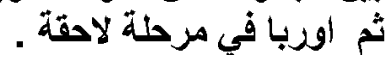

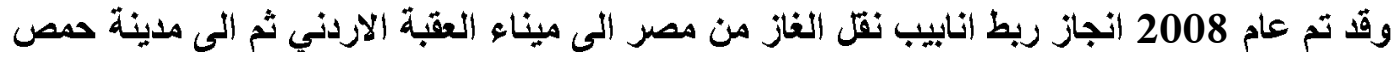

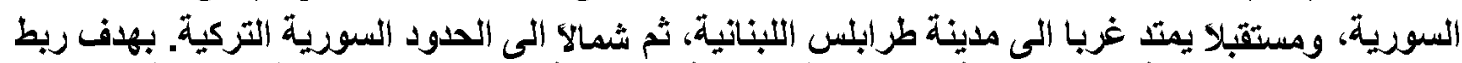

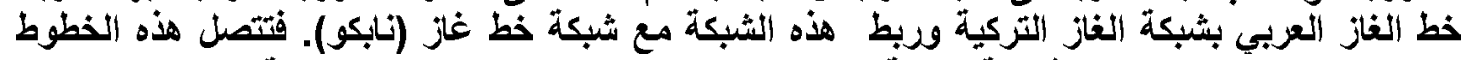

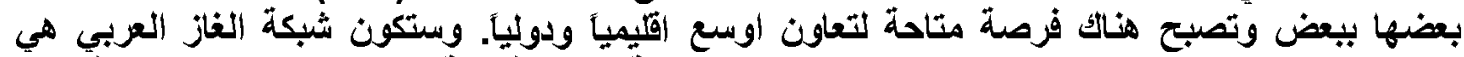

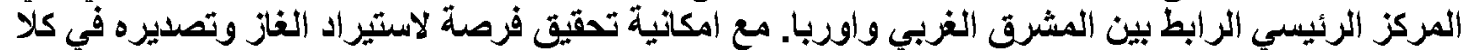

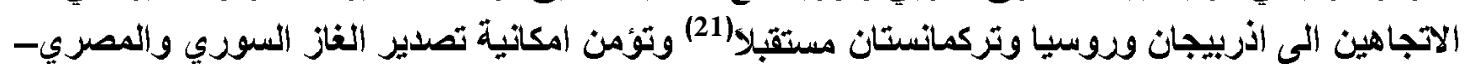

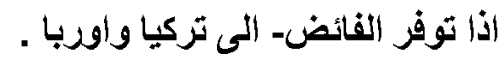

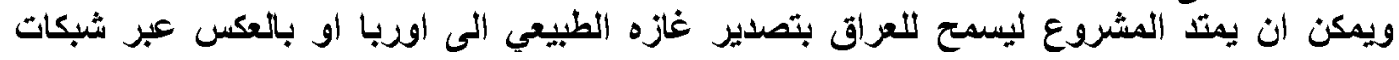

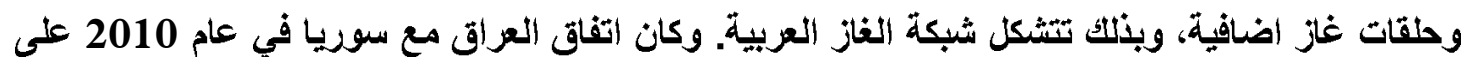

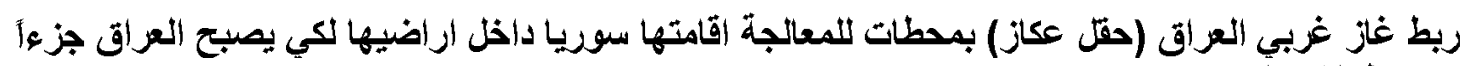

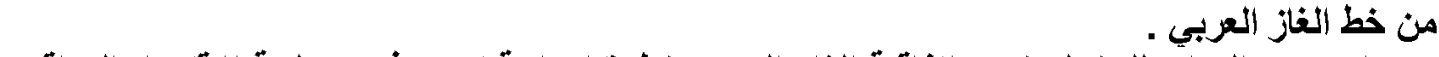

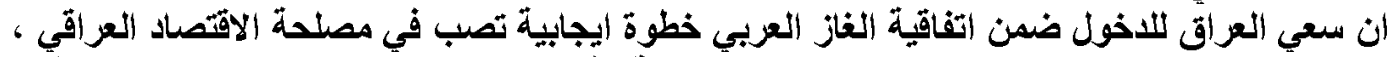

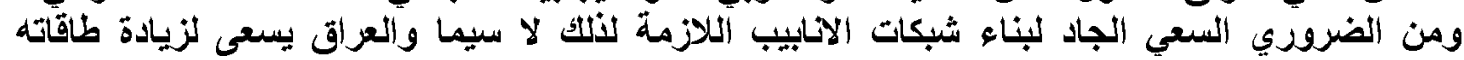

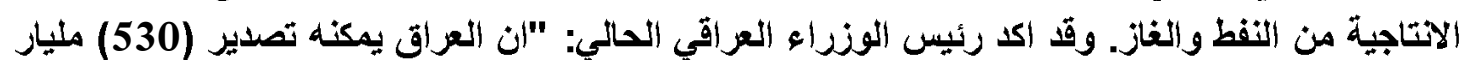

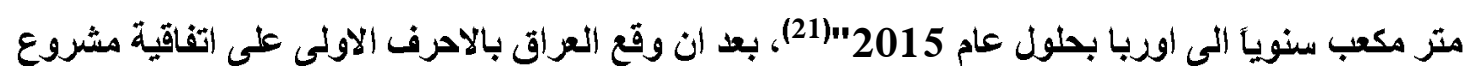

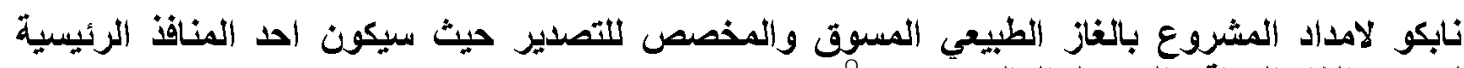

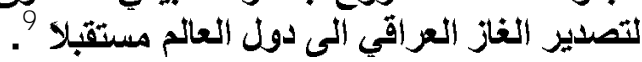

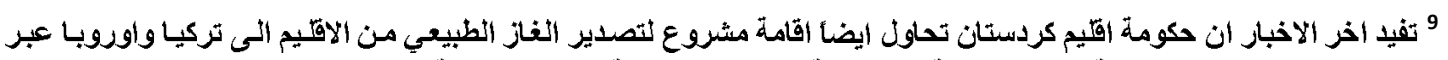

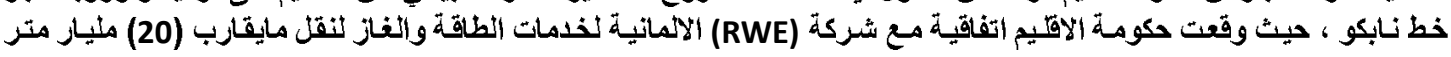

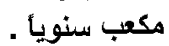

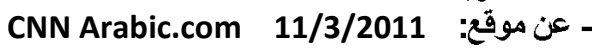




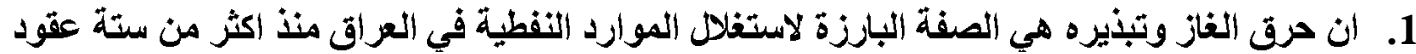

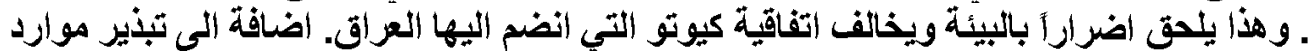

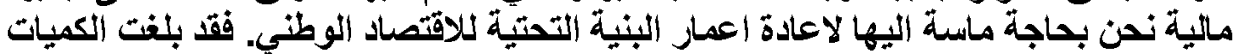

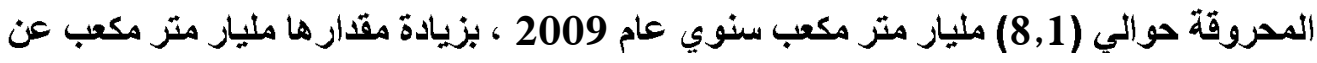

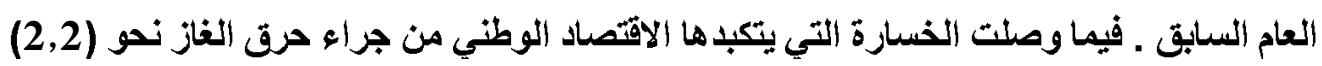

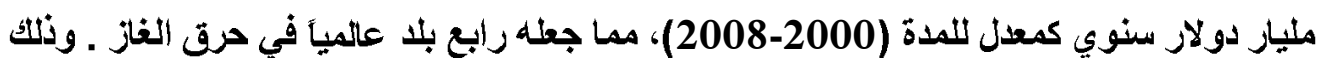

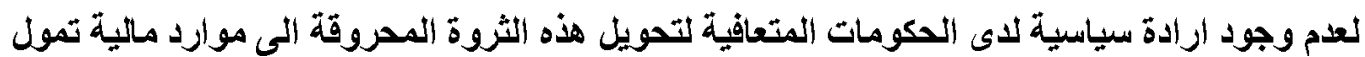

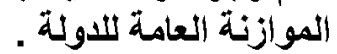

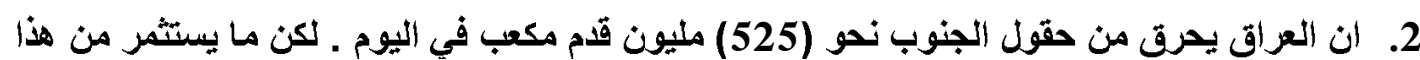

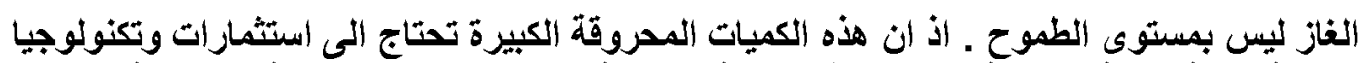

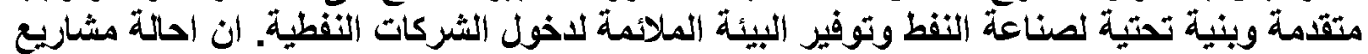

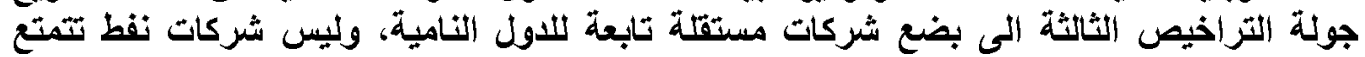

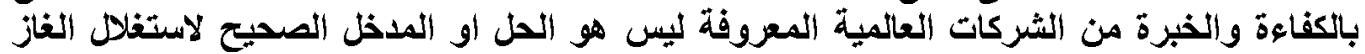

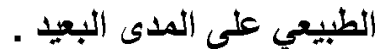

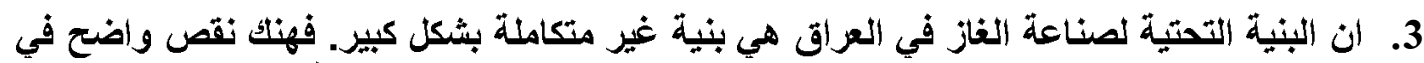

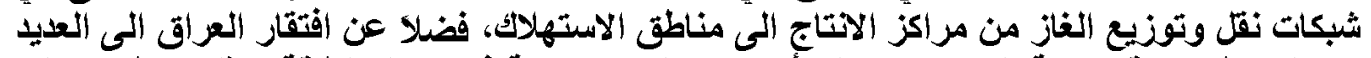

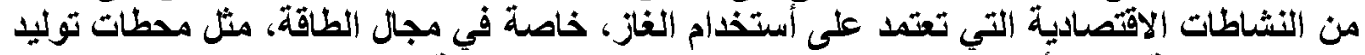

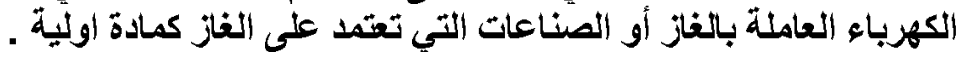


1. ضرورة اعادة تأهيل منشآت ومعامل استثمار الغاز الطبيعي المعطلة مع بناءء مشاريع جديدة قادرة

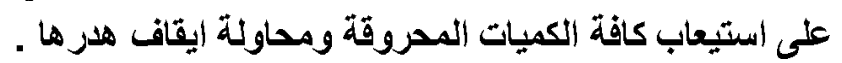

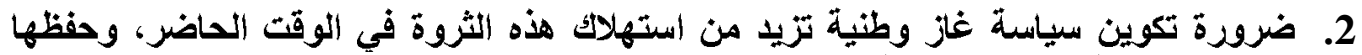

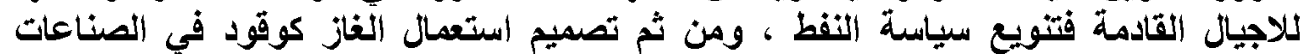

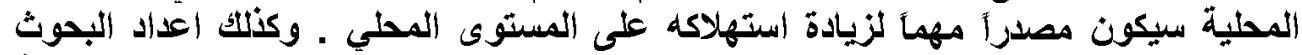

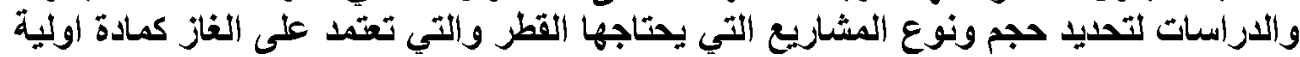
في منتجاتها .

3. اكمال بناء شبكات نقل وتوزيع الغاز بهدف ايصال الغاز اللى مراكز الاستهلاك المحلى ومحطات

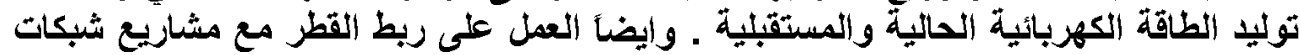

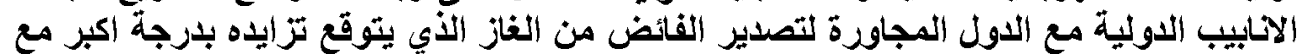

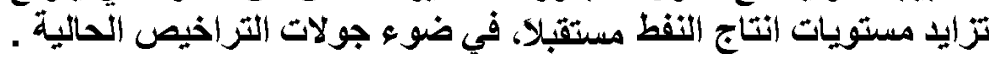

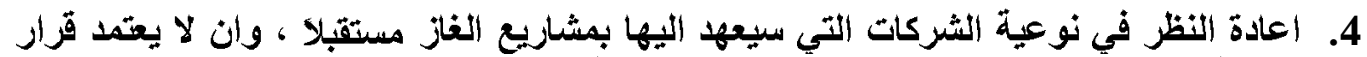

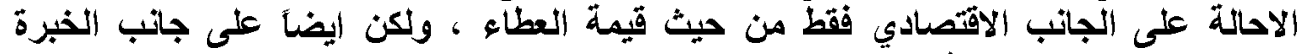
والكفاءة التي تتمتع بها هذه الثُ الثركات .

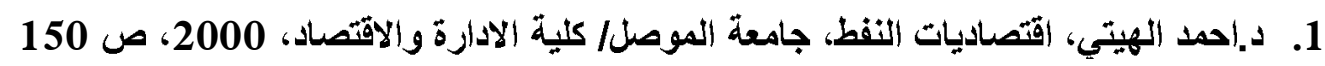

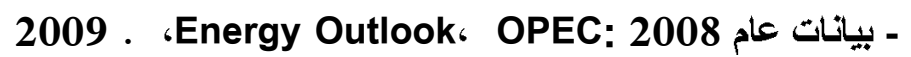

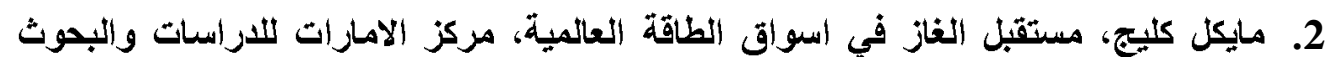

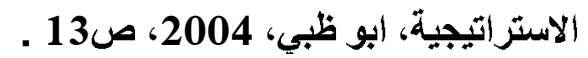

3. عبد الرحن خليل الجوهري، الغاز الطبيعي في العالم العربي، بحث منشور في كتاب دراسات

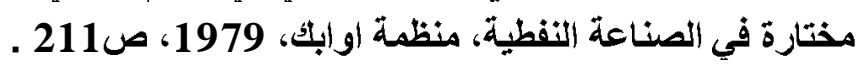

4. http://argaam.com, 30/01/2011

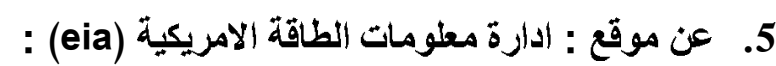

2. eia, Iraq Energy Data, statistics and Analyses، http://www.eai.done.gov 01/12/2010

6. وزارة التخطيط والتعاون الانمائي، اللجنة الفنية لاعداد الخطة الوطنية الخمسية

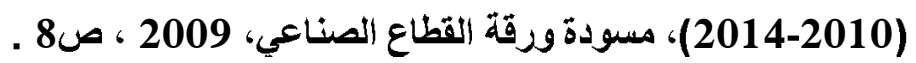

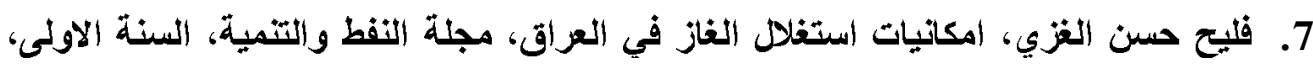
العدد/ 12، ايلول 1976، ص474.

8. موقع منظمة اوابك، خلاصة المعومات المتوفرة عن قطاع النفط في الجمهرية العراقية،

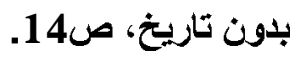
9. دمحد علي زيني، الاقتصاد العراقي بين الماضي والحاضر وخيارات المستقبل، دار الملاكت

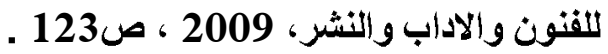


10. موارد الثاز الطبيعي في الدول العربية، منظمة الاقطار العربية المصدرة للبترول (اوابك)،

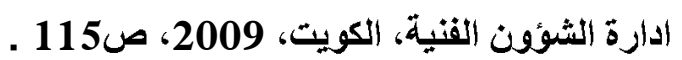

11. وندل بروير، الهدف المحير للحد من محارق الغاز، موقع شركة مثل النفية (shell) ؛

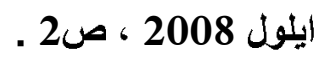

12. وكالة الصحافة المستقلة، خبراء : (70\%) من غاز العراق يحرق يومياً بلا جدوى ـ عن .

www.ipairaq.com, 28/01/2011

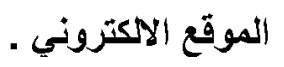

13. د.حسين الثهرستاني، ندوة الآفاق المستقبلية لصناعة النفط في العراق، مركز العراق

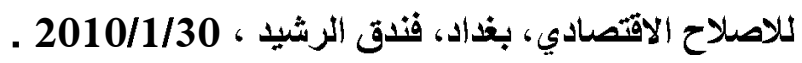

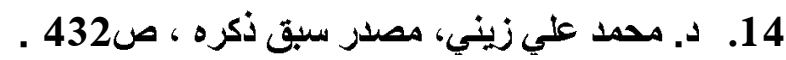

15. شل تحنر من زيادة كميات الغاز المحروق مع زيادة الاتتاج النفطي على الر ابط التالي : http://orgin.iraqhurr.org, 30/01/2011.

$$
\text { 16. جريدة القبس الكويتية، العدد/13433 ، 2010/10/21 ـ }
$$

$$
\text { - وايضاً موقع وزارة النفط العراقية الاكتئة العتروني . }
$$

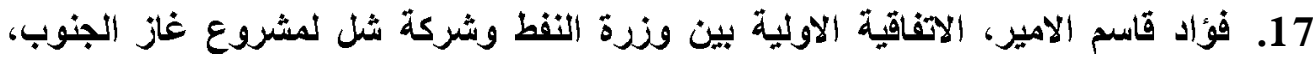

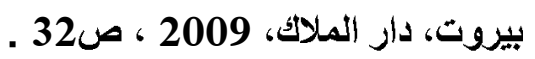

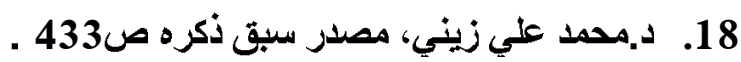

19. تثارير عزاقية، تأسيس شركة عزاقية للغاز المصاحب، مجلة حوار، السنة الخامسة،

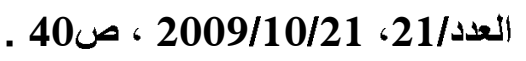

20. جهورية مصر العربية، وزارة البترول. على الرابط : www.pefroleam.gov.eglav $/, 8 / 12 / 2010$.

21. موقع ادارة معلومات الطاقة الامريكية (eia) مصدر سبق ذكره . 
1. الهيتي، احمد حسين. اقتصاديات النفط. جامعة الموصل، كلية الادارة والاقتصاد، 2000. 2. زيني، محمد على الاقتصاد العراقي الماضي والحاضر وخيارات المستقبل، ط3، بذاداد، دار

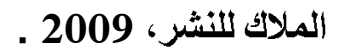
3. الامير، فؤاد قاسم. الاتفاقية الاولية بين وزرة النفط وشركة شل لمشروع غاز الجنوب، بيروت، دار الملاك للنشر، 2009.

4. القيسي، محمد. دراسات في اقتصاديات البترول. الكويت، مؤسسة الوحدة للنشر، 1979.

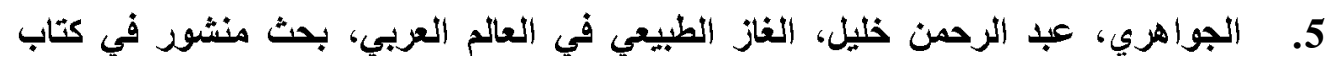
"دراسات مختارة في الصناعة النفطية"، منظمة اوابلث، الكويت، 1979.

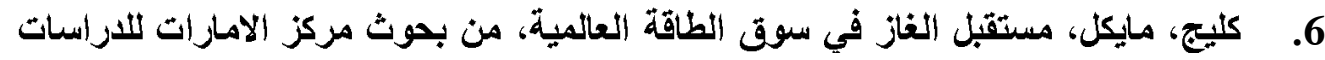
والبحوث الاستراتيجية ، ط1، ابو ظبي ، 2004. 7.

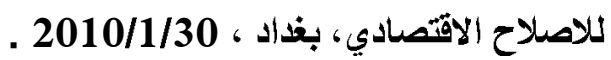
8. منظمة اوابك، ادارة الثؤون الفنية، تنمية موارد الغاز الطييعي في الاول العربية، الكويت، .2009

9.

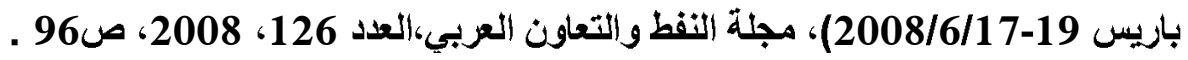
10. منظمة او ابك ، خلاصة المطومات المتوفرة عن قطاع النفط في الجمهورية العراقية، بدون تاريخ . 11. الورقة القطرية لجمهورية العراق ، مؤتمر الطاقة العربي الثامن ، الاردن، 2008 ـ

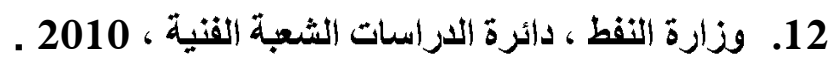

13. وزارة التخطيط والتعاون الانمائي، اللجنة الفنية لاعداد الخطة الوطنية التئية الخمسية (2014-2010)، مسودة ورقة قطاع الصناعي، الاصدار الثاني، اعداد لجنة قطاع الصناعة .2009 ، 20 14. وزارة التخطيط والتعاون الانمائي، الجهاز المركزي للاحصاء ، سنوات متفرقة .

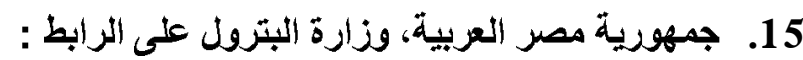
www.pefroleam.gov.eglav/, 8/12/2010.

16. التزي، فليح حنن، امكاثيات استغلال الثاز في العراق، مجلة النفط والتمية، السنة الاولى،

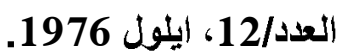

17. جريدة القبس الكويتية، العد/2010/1393 في 2010/10/21 من موقع وزارة النفط العراقية بتاريخ 2010/12/10

18. BP. Statistical Review of World Energy, June, 2009.

19. http://argaam.com, 30/01/2011 
20. eia, Iraq Energy Data, statistics and Analysis. From: http://www.eai.done.gov 01/12/2010

21. وندل برويز، الهنف المحير للحد من محارق الغاز، موقع شركة شل، ايلول 2008.

22. World Bank, Estimated Flared Volumes From Satellite Data. From : http://worldBank.org 27-01-2011.

23. وكالة الصحافة المستقلة : خبراء (70\%) من الغاز العراقي يجزي حرقه بلا جدوى ويلحق

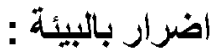

http://www.ipairaq.com, 28.01.2011

24. شل تحنر من زيادة كميات الغاز المحروق مع زيادة الاتتاج : http://origin.Iraqhurr.org, 30.01.2011.

25. OPEC. Energy Outlook, 2009. 